\title{
HIDRÓLISE ENZIMÁTICA DE MANDIOCA E PUBA PARA A OBTENÇÃO DE XAROPE DE MALTOSE
}

\author{
MARIANA DE PAULA EDUARDO
}

\begin{abstract}
Dissertação apresentada à Escola Superior de Agricultura "Luiz de Queiroz", Universidade de São Paulo, para obtenção do título de Mestre em Ciências, Área de Concentração: Ciência e Tecnologia de Alimentos.
\end{abstract}

PIRACICABA

Estado de São Paulo - Brasil

Novembro - 2002 


\title{
HIDRÓLISE ENZIMÁTICA DE MANDIOCA E PUBA PARA A OBTENÇÃO DE XAROPE DE MALTOSE
}

\author{
MARIANA DE PAULA EDUARDO
}

Engenheira de Alimentos

Orientador: Prof. Dr. TOBIAS JOSÉ BARRETO DE MENEZES

Dissertação apresentada à Escola Superior de Agricultura "Luiz de Queiroz", Universidade de São Paulo, para obtenção do título de Mestre em Ciências, Área de Concentração: Ciência e Tecnologia de Alimentos.

PIRA CICABA

Estado de São Paulo - Brasil

Novembro - 2002 


\title{
Dados Internacionais de Catalogação na Publicação (CIP)
} DIVISÃO DE BIBLIOTECA E DOCUMENTAÇÃO - ESALQ/USP

\author{
Eduardo, Mariana de Paula \\ Hidrólise enzimática de mandioca e puba para a obtenção de \\ xarope de maltose / Mariana de Paula Eduardo. - - Piracicaba, 2002. \\ $54 \mathrm{p}$. \\ Dissertação (mestrado) - - Escola Superior de Agricultura Luiz de \\ Queiroz, 2002. \\ Bibliografia.

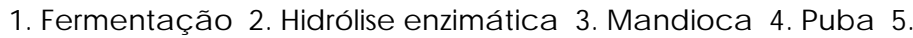 \\ Xarope de maltose I. Título
}

CDD 664.114

"Permitida a cópia total ou parcial deste documento, desde que citada a fonte - $\mathrm{O}$ autor" 


\section{AGRADECIMENTOS}

Ao Prof. Dr. Tobias José Barreto de Menezes pela orientação.

À Capes pela concessão de bolsa de estudos.

À empresa Quest pela doação das enzimas Canalpha 5000P e Bioferm P, utilizadas no experimento.

Ao Prof. Dr. Jorge Horii pela utilização do laboratório, apoio, colaboração e amizade.

À Prof. Drª . Silene Bruder Silveira Sarmento pela colaboração e sugestões.

À Prof. Drª . Marilia Oetterer pelo incentivo e amizade.

Às bibliotecárias Beatriz, Midian e Ligiana, pelo auxílio na organização das referências bibliográficas e normalização da dissertação.

Aos técnicos de laboratório, Carlota, Regina, Rose e Silvino pelo auxílio e colaboração prestados nos momentos necessários.

Aos funcionários da Biblioteca Central e Seção de Pós-Graduação pelos esclarecimentos e ajuda para a apresentação desta dissertação. 
Aos meus amigos André, Anny, Antonio, Carlos, Juliana, Patrícia, Roberta, Solange e todos aqueles que contribuíram de alguma forma para a realização do trabalho.

À minha mãe Brigitte Feigl por toda paciência e auxílio na elaboração e correção do trabalho.

Ao meu marido Rodrigo Ohara pela compreensão e companheirismo.

À minha família por todo apoio e compreensão.

À todas as pessoas e instituições que de alguma forma, direta ou indiretamente, colaboraram para a realização deste trabalho. 


\section{SUMÁRIO}



Página

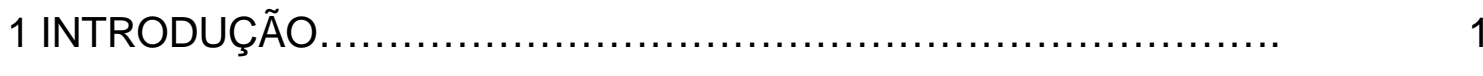

2 REVISÃO DE LITERATURA..................................... 3

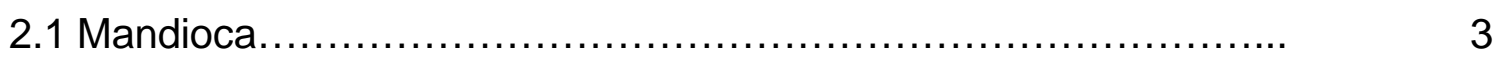

2.2 Fermentação da mandioca para produção de puba................. 5





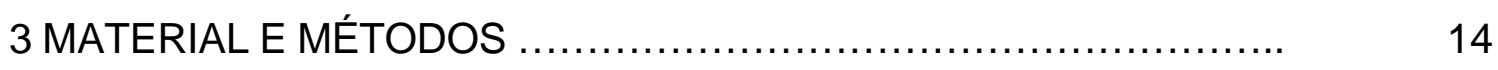

3.1 Material...................................................... 14

3.1.1 Matéria prima............................................. 14

3.1.1.1 Preparo das raspas de mandioca............................ 14

3.1.1.2 Preparo da Puba.......................................... 14

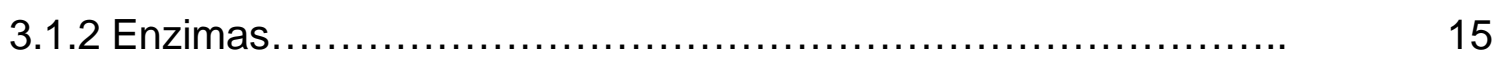

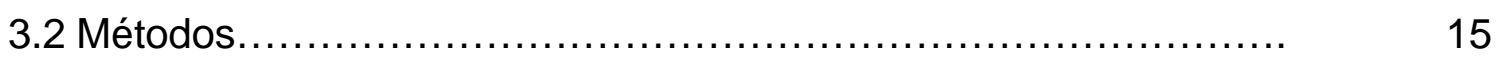

3.2.1 Produção dos hidrolisados................................... 15

3.2.1.1 Preparação das amostras................................... 16

3.2.1.2 Gelatinização................................................. 18

3.2.1.3 Liquefação.................................................. 18



3.2.1.5 Centrifugação............................................ 18 
3.2.2 Análise dos hidrolisados ......................................... 19

3.2.2.1 Matéria seca ................................................ 19

3.2.2.2 Dextrose equivalente (DE) ................................... 19

3.2.2.3 Eficiência de hidrólise ......................................... 20

3.2.2.4 Análise cromatográfica......................................... 20

3.2.2.5 Balanço de massa............................................. 21

3.2.3 Delineamento experimental.................................... 21

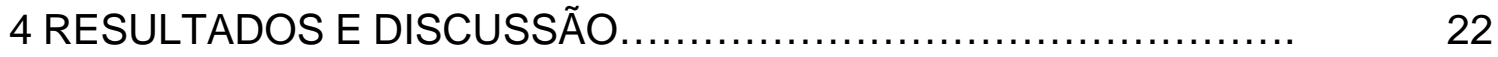

4.1 Produção dos hidrolisados ........................................... 22

4.1.1 Preparo de matéria-prima ...................................... 22

4.1.2 Concentração de sólidos ........................................ 23

4.1.3 Gelatinização..................................................... 23

4.1.4 Liquefação ................................................... 24

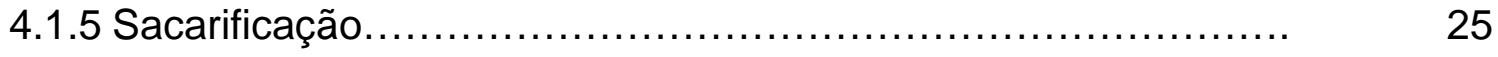

4.1.6 Separação de sólidos dos hidrolisados.............................. 26

4.2 Composição do xarope ................................................ 26

4.2.1 Matéria seca.................................................. 26

4.2.2 Dextrose Equivalente (DE) ................................... 27

4.2.2.1 Mandioca......................................................... $\quad 27$

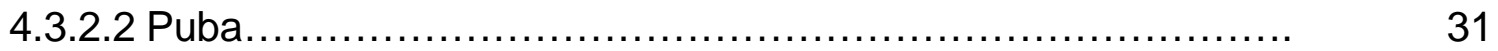

4.2.3 Perfil de açúcares................................................ $\quad 34$

4.2.4 Eficiência de hidrólise .............................................. 37

4.2.5 Balanço de massa ............................................. 38



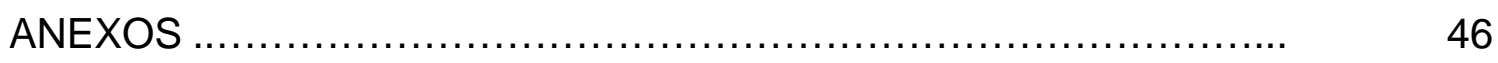

REFERÊNCIAS BIBLIOGRÁFICAS ................................. 50 


\section{LISTA DE TABELAS}

Página

1 Composição centesimal em base seca de mandioca, milho

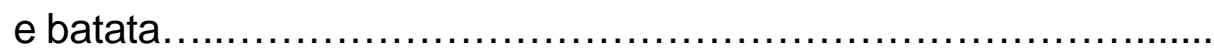

2 Composição dos diferentes tipos de xarope de maltose e

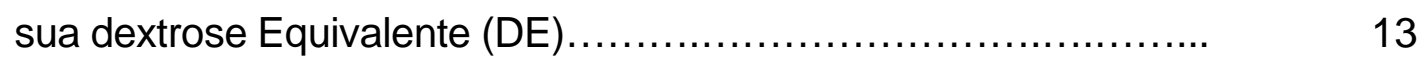

3 Conteúdo de sólidos nas amostras de mandioca........................ 27

4 Dextrose equivalente nas amostras de mandioca após a

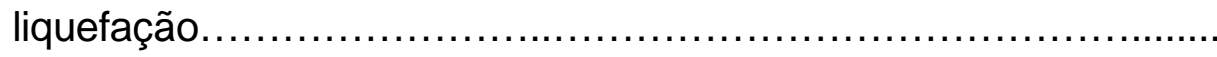

5 Influência da concentração de sólidos da mandioca e do tempo de sacarificação nos índices de DE ............................ $\quad 30$

6 Dextrose equivalente nas amostras de puba após a liquefação.......

7 Influência da concentração de sólidos da puba e do tempo de sacarificação nos índices de DE.....................................

8 Perfil de açúcares (em base seca) e DE dos tratamentos

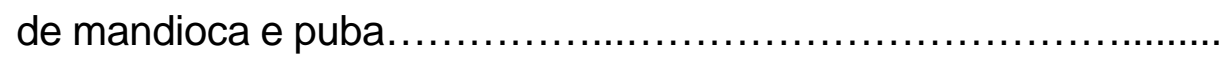

9 Rendimento da hidrolise do amido contido nas amostras de mandioca e puba................................................. $\quad 37$

10 Balanço de massa dos tratamentos da mandioca....................... 40

11 Balanço de massa dos tratamentos da puba............................ 41 


\section{LISTA DE FIGURAS}

Página

1 Características das enzimas envolvidas na hidrólise do amido........

2 Esquema das ligações glicosídicas presentes em cadeias de

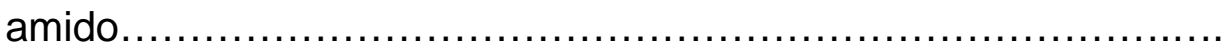

3 Estruturas das cadeias componentes do amido: amilose e amilopectina

4 Fluxograma de produção de xarope de maltose com diferentes

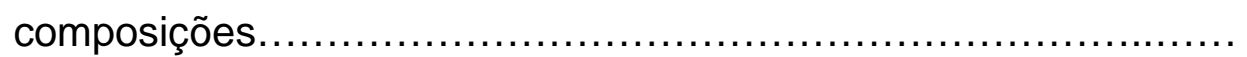

5 Fluxograma de produção dos hidrolisados de mandioca e puba..... 16

6 Esquema de codificação das amostras................................ 17

7 Curvas de sacarificação das amostras de mandioca.................... 29

8 Curvas de sacarificação das amostras de puba......................... 32

9 Fluxograma do balanço de massa do tratamento 20/10 da puba.... 39 


\title{
HIDRÓLISE ENZIMÁTICA DE MANDIOCA E PUBA PARA A OBTENÇÃO DE XAROPE DE MALTOSE
}

\author{
Autora: MARIANA DE PAULA EDUARDO \\ Orientador: Prof. Dr. TOBIAS JOSÉ BARRETO DE MENEZES
}

\section{RESUMO}

Atualmente o consumo de xarope de maltose vem crescendo devido ao seu uso em cervejarias e está substituindo progressivamente os adjuntos amiláceos. O xarope de maltose é, tradicionalmente, produzido por meio da hidrólise ácida e/ou enzimática de amido ou flocos de milho. Este trabalho teve como objetivo analisar a possibilidade de obtenção de maltose a partir de outras matérias-primas amiláceas como a mandioca e a puba (produto derivado da fermentação da mandioca) pela ação da $\alpha$-amilase bacteriana e da $\alpha$-amilase fúngica sem que fosse necessária a extração do amido. Amostras de mandioca e puba com 10, 20 e $30 \%$ de sólidos foram incubadas com $\alpha$-amilase bacteriana termoestável durante 10,20 e 30 minutos a $80^{\circ} \mathrm{C}$, adicionando-se em seguida, $\propto$-amilase fúngica e incubando-se as amostras durante 48 horas a $55^{\circ} \mathrm{C}$. O grau de sacarificação, expresso em dextrose equivalente (DE), foi determinado pelo método DNS em vários intervalos de tempo. Glicose e maltose foram determinadas por HPLC após 48 horas de sacarificação. Os resultados mostraram que o tempo de ação da $\alpha$-amilase bacteriana não causou diferenças significativas no grau de hidrólise entre as amostras, mas a 
concentração de sólidos influiu significativamente no grau da liquefação das amostras. O comportamento das curvas do grau de sacarificação foi semelhante para todos os tratamentos tanto da mandioca quanto da puba. $O$ conteúdo de maltose nas amostras variou entre $30-60 \%$ e a glicose entre $0-10 \%$ caracterizando um xarope com alto teor de maltose. A eficiência de hidrólise ficou abaixo do esperado. Entretanto, esse fato pode ser explicado pela utilização da mandioca sem extração prévia do amido e pelas dificuldades na extração dos sólidos por centrifugação. Pode-se afirmar que tanto a mandioca quanto à puba podem ser utilizadas como matéria prima em substituição ao milho na obtenção de xarope de maltose através da hidrólise enzimática. A puba, porém, é de mais fácil manuseio sendo que o tratamento com $20 \%$ de sólidos, exposto durante 10 minutos a $\alpha$-amilase bacteriana proporcionou maior rendimento, atingindo $4,2 \mathrm{~kg}$ de maltose e $0,3 \mathrm{~kg}$ de glicose por $100 \mathrm{~kg}$ de mandioca fresca além de proporcionar menor quantidade de resíduo sólidos de $13,7 \mathrm{~kg}$. 


\title{
ENZYMATIC HYDROLYSIS OF CASSAVA AND PUBA FOR MALTOSE SYRUP PRODUCTION
}

\author{
Author: MARIANA DE PAULA EDUARDO \\ Adviser: Prof. Dr. TOBIAS JOSÉ BARRETO DE MENEZES
}

\section{SUMMARY}

Nowadays the consumption of maltose syrups is increasing due to its utilization in breweries where it replaces starch adjuncts. Traditionally maltose syrup has been produced from cornstarch or pellets using acid and/or enzymatic hydrolysis. The objective of this work was to evaluate the possibility of obtaining maltose from starch sources other than maize, such as cassava roots or puba, a fermented cassava product, without extraction of the starch, using bacterial $\alpha$ amylase and fungal $\alpha$-amylase for starch hydrolysis. Cassava and puba samples with 10, 20 and $30 \%$ dry matter were incubated with termostable bacterial $\alpha$-amylase for 10,20 and 30 minutes at $80^{\circ} \mathrm{C}$, followed by the addition of fungal $\alpha$-amylase. The samples were incubated for 48 hours at $55^{\circ} \mathrm{C}$. The degree of saccharification, expressed as dextrose equivalent (DE), was determined by the DNS method. The glucose and maltose contents of the hydrolysate were determined after 48 hours by HPLC. The results showed that the time of action of $\alpha$-amylase did not influence the degree of saccharification of the samples but the solids concentration significantly affected the hydrolysis degree. The saccharification degree curves were similar for both cassava and 
puba. The maltose content of the samples varied between $30-60 \%$ and the glucose content between $0-10 \%$, which characterized them as "High maltose syrups". The hydrolysis efficiency was lower than expected. However, this fact could be explained by the use of cassava without extraction of the starch and by the difficulty of extracting the solids by centrifugation. It was concluded that for replacement of corn starch, both cassava roots and puba could be used as raw materials for maltose syrup production by enzymatic hydrolysis. However the puba was easier to handle than cassava. The puba treatment consisting of $20 \%$ of solids and 10 minutes exposure to $\alpha$-amylase gave the highest yield reaching $4.2 \mathrm{~kg}$ of maltose and $0.3 \mathrm{~kg}$ of glucose per $100 \mathrm{~kg}$ of raw cassava, in addition to a lower solids residue of $13.7 \mathrm{~kg}$. 


\section{INTRODUÇÃO}

A maltose é um ingrediente utilizado na indústria de alimentos, principalmente em balas, sorvetes, refrigerantes, embutidos e na panificação. É tradicionalmente produzido através da hidrólise ácida e/ou enzimática de amido ou flocos de milho.

Atualmente, o consumo de xarope de maltose vem crescendo no país uma vez que, em cervejarias, está substituindo progressivamente os adjuntos amiláceos trazendo ganhos econômicos na simplificação do processo de preparação do mosto a ser fermentado (Venturini Filho \& Cereda , 1998).

Embora a produção do xarope de maltose no Brasil esteja restrita a poucas empresas que detém a tecnologia de hidrólise enzimática do amido e utilizam o milho como fonte de carboidrato, outras matérias-primas amiláceas também podem ser utilizadas. Entre elas a mandioca, largamente cultivada no Brasil, apresenta excelentes possibilidades de substituir o milho. Cultura de elevada produtividade agrícola, com alto teor de amido e de fácil propagação é ainda tolerante a pragas e doenças e pouco exigente quanto a condições de solo e de clima. Com o propósito de se dispor de uma alternativa ao milho a utilização da mandioca como matéria-prima traria como benefício aos produtores uma diversificação mais ampla e agregaria maior valor aos produtos derivados como aconteceu durante a crise energética na década de 70 quando a raiz foi utilizada como fonte de carboidratos para a produção de álcool, juntamente com a cana-de-açúcar (Camargo, 1985).

A utilização da mandioca poderia ser ainda facilitada se 0 amido estivesse mais disponível à ação das enzimas hidrolíticas do que normalmente 
se encontra na raiz crua. Embora haja métodos mecânicos, freqüentemente dispendiosos, que rompem a barreira lignocelulósica, a fermentação das raízes também desintegraria esses componentes fibrosos que agem como obstáculo à penetração de calor, diminuindo, conseqüentemente, o custo de produção do xarope. Apesar da pubagem aumentar o tempo de preparo, um cozimento mais brando seria capaz de hidratar os grânulos de amido sem a necessidade da cominuição da matéria-prima, melhorando, assim, o balanço energético.

Este trabalho tem por finalidade estabelecer parâmetros de obtenção do hidrolisado do amido da mandioca crua e fermentada (puba) verificando o efeito da concentração de sólidos e do tempo de exposição da $\alpha$-amilase bacteriana quanto à composição, ao grau de sacarificação e ao rendimento do produto final a fim de obter um xarope com características similares ao xarope de maltose obtido a partir do milho. 


\section{REVISÃO DE LITERATURA}

\subsection{Mandioca}

A produção de plantas amiláceas supre $4 / 5$ da demanda mundial de alimentos em termos de calorias (Sarikaya et al.., 2000). A mandioca (Manihot esculenta Crantz), uma raiz com alto conteúdo de amido, apresenta mais de trezentas variedades e é originária do Continente Americano, provavelmente Brasil, América Central ou México (Mendes, 1992). Pertence à família das Euforbiáceas, a mesma da mamona, seringueira, coroa-de-cristo e flor-depapagaio (Camargo, 1985).

Nove países produzem $80 \%$ das 168 milhões de toneladas de mandioca colhidas por ano (Empresa Brasileira de Pesquisa Agropecuária - EMBRAPA, 2002). O maior produtor é a Nigéria com aproximadamente 33 milhões de toneladas por ano seguida do Brasil com 25 toneladas por ano; em seguida aparecem a Tailândia, Congo, Indonésia, Gana, Tanzânia, Índia e Moçambique (EMBRAPA, 2002). A produção brasileira vem se mantendo constante desde 1980 (Instituto Brasileiro de Geografia e Estatística - IBGE, 1996).

A mandioca é a sexta mais importante planta comestível no mundo (Berghofer \& Sarhaddar, 1988) e ocupa o quarto lugar em área plantada com mais de 500 milhões de consumidores regulares (Camargo, 1985). Apresenta um bom rendimento de agrícola com 13,5 tha enquanto que o milho produz apenas 3 t/ha (IBGE, 2002) A área plantada de mandioca no país é de 1,7 milhões de hectares enquanto que a do milho é de 12 milhões de hectares que produzem 42 milhões de toneladas (EMBRAPA, 2002). 
A composição da mandioca varia muito com a espécie, idade e condições de cultivo. A Tabela 1 mostra a composição da mandioca em comparação com a do milho e a da batata que também são usados como matéria-prima na produção de xaropes.

Tabela 1. Composição centesimal em base seca de mandioca, milho e batata.

\begin{tabular}{lccc}
\hline & Mandioca $^{1}$ & Milho $^{2}$ & Batata $^{2}$ \\
\hline Amido (\%) & 90,1 & 70,9 & 76,0 \\
Proteína (\%) & 1,5 & 9,8 & 8,0 \\
Fibra (\%) & 5,6 & 2,6 & 6,4 \\
Gordura (\%) & 0,3 & 4,8 & 0,5 \\
Açúcares (\%) & 0,7 & 2,6 & 4,4 \\
Cinzas (\%) & 1,8 & 1,4 & 4,7 \\
Outros (\%) & - & 7,9 & - \\
\hline
\end{tabular}

${ }^{1}$ Mendes (1992)

${ }^{2}$ Dziedzic \& Kearsley (1984)

Por apresentar levado teor de amido e baixos teores de gorduras, proteínas e cinzas (Kearsley \& Tabiri, 1979) a mandioca é uma matéria-prima adequada para obtenção, por hidrólise, de diversos derivados, além disso, o amido de mandioca é mais suscetível a ação da $\alpha$-amilase bacteriana do que o milho provavelmente devido à sua temperatura de gelatinização ser mais baixa $\left(58-75^{\circ} \mathrm{C}\right)$ e porque os grãos de amido da mandioca possuem uma estrutura interna fracamente ligada (Park et al., 1971).

A cultura da mandioca é de fácil propagação, tolerante a pragas e doenças e pouco exigente quanto a condições edafoclimáticas. No entanto, tem baixa resistência ao frio, apresenta um longo período de crescimento e alto potencial de deterioração fora do solo. As mudanças ocorrem após 2 a 3 dias 
da colheita devido a processos fisiológicos seguida pela deterioração microbiológica após 5 a 7 dias devido ao elevado teor de umidade (Plumbley \& Rickard, 1991). A conservação porém, pode ser feita por meio do processamento em farinha, pellets e raspas secas (Ghildyal et al., 1989) ou como é muito usual nas pequenas propriedades do Brasil, processando a raiz para obter polvilho, puba, biju entre outros produtos regionais.

\subsection{Fermentação da mandioca para produção de puba}

Puba é o produto da fermentação natural de raízes inteiras de mandioca, com ou sem película, produzida principalmente no Nordeste do Brasil e utilizada apenas como alimento regional (Mendes, 1992).

No processo mais rudimentar, as raízes são colocadas em água sem agitação durante três a sete dias, dependendo de vários fatores como temperatura, $\mathrm{pH}$, variedade, etc.., até que amoleçam e comecem a soltar a casca.

Em processos mais sofisticados controla-se a temperatura próxima de $35^{\circ} \mathrm{C}$ podendo ainda ser utilizadas culturas puras de microrganismos (starters) ou pré-inóculo da fermentação anterior para a diminuição do tempo de pubagem.

Segundo Almeida (1992) a fermentação natural da mandioca é principalmente acética, láctica e butírica ocorrendo formação de compostos aromáticos e o amolecimento das raízes.

A puba pode ser desidratada e, em seguida utilizada na confecção de bolos, cuscuz e pudins. etc. (Mendes, 1992).

\subsection{Enzimas}


Existem cinco grupos de enzimas envolvendo a hidrólise de amido: as endo e exo amilases, as desramificadoras, as isomerases e as ciclodextrinas glicosiltransferases (Maldonado \& Lopez, 1995). As principais enzimas envolvidas na hidrólise do amido são mostradas na Figura 1.

\begin{tabular}{|c|c|c|c|c|c|}
\hline Tipo & Nome comum & $\begin{array}{l}\text { Microrganismos } \\
\text { produtores }\end{array}$ & Substrato & \multicolumn{2}{|c|}{$\mathrm{pH}^{2}{ }^{0} \mathrm{C}$} \\
\hline Endo-amilase & $\begin{array}{l}\text { Amilase } \\
\text { bacteriana } \\
\text { Amilase fúngica }\end{array}$ & $\begin{array}{l}\text { B. subtilis } \\
\text { B. licheniformis } \\
\text { A. oryzae }\end{array}$ & $\begin{array}{l}\alpha-1,4-\text { glicosil } \\
\alpha-1,4-\text { glicosil } \\
\alpha-1,4 \text {-glicosil }\end{array}$ & $\begin{array}{c}6.0 \\
5.0-7.0 \\
4.5\end{array}$ & $\begin{array}{c}65-70 \\
90 \\
50-60\end{array}$ \\
\hline Exo-amilase & $\begin{array}{l}\text { Amiloglucosidase } \\
\beta \text {-amilase bacter. }\end{array}$ & $\begin{array}{l}\text { A. niger } \\
\text { Bacillus sp. } \\
\text { Clostridium sp. }\end{array}$ & $\begin{array}{l}\alpha-1,4-\text { glicosil } \\
\alpha-1,6-\text { glicosil } \\
\alpha-1,4-\text { glicosil } \\
\alpha-1,4-\text { glicosil }\end{array}$ & $\begin{array}{l}4.0-5.0 \\
5.0 \\
5.5-6.0\end{array}$ & $\begin{array}{c}60 \\
55-60 \\
75-85\end{array}$ \\
\hline$\alpha$-1,6-amilase & $\begin{array}{l}\text { Pululanase } \\
\text { Isoamilase }\end{array}$ & $\begin{array}{l}\text { K. aerogenes } \\
\text { Pseudomonas sp }\end{array}$ & $\begin{array}{l}\alpha-1,6-\text { Maltotriosil } \\
\alpha-1,6-\text { Heptasac. }\end{array}$ & $\begin{array}{l}5.0 \\
4.0\end{array}$ & $\begin{array}{c}60 \\
50-55\end{array}$ \\
\hline Isomerase & $\begin{array}{l}\text { Glicose } \\
\text { isomerase }\end{array}$ & B. circulans & $\begin{array}{l}\text { Aldo/ceto pentose } \\
\text { Aldo/ceto hexose }\end{array}$ & 8.2 & 65 \\
\hline
\end{tabular}

Figura 1 - Características das enzimas envolvidas na hidrólise do amido.

Fonte: Maldonado \& Lopez (1995)

O xarope de maltose é geralmente produzido em três fases: a gelatinização e a liquefação em altas temperaturas usando uma $\alpha$-amilase termoestável (bacteriana) ocorrendo em seguida a sacarificação na presença de uma $\beta$-amilase ou uma $\alpha$-amilase fúngica. A etapa da gelatinização é necessária para intumescer os grânulos de amido e torna-los suscetíveis pois geralmente as $\alpha$ - e $\beta$-amilases não agem com eficiência nos grânulos crus que são resistentes æ̀̀ enzimas (Sarikaya et al., 2000). A $\alpha$-amilase bacteriana atua na liquefação agindo em toda a molécula "quebrando-a" em moléculas menores. A sacarificação para a produção de maltose é feita por uma $\beta$-amilase ou $\alpha$-amilase fúngica que atua nas moléculas de amido a partir da extremidade 
redutora "separando" as moléculas de maltose. Utilizando essas enzimas é possível produzir xaropes com até $60 \%$ de maltose (Maldonado \& Lopez, 1995). Se for necessária a produção de xarope com altíssimo teor de maltose pode-se utilizar também uma enzima desramificadora que rompe as ligações glicosídicas $\alpha-1,6$ da amilopectina uma vez que as $\alpha$-amilases não conseguem rompe-las.(Kearsley \& Tabiri, 1979; Maldonado \& Lopez, 1995). Uma enzima desramificadora que também pode ser usada é a isoamilase da Flavobacterium $s p$ (Sato \& Park , 1980).

\subsection{Xarope de Maltose}

A maltose é um dissacarídeo redutor formado por duas moléculas de glicose unidas por ligações $\alpha-1,4$. É o elemento estrutural básico da composição do amido (Bobbio \& Bobbio, 1992).

O amido é constituído de moléculas de glicose unidas em ligações $\alpha-1,4$ e $\alpha-1,6$ (Figura 2) e é uma mistura de dois polissacarídeos denominados amilose e amilopectina. 




Figura 2 - Esquema das ligações glicosídicas presentes em cadeias de amido.

A amilose é uma cadeia linear de moléculas de glicose unidas apenas por ligações $\alpha-1,4$ (Figura 3 ) enquanto que a amilopectina é constituída de várias cadeias curtas de amilose de aproximadamente 20 unidades de glicose unidas entre si através de 4 a $6 \%$ de pontos de ligações $\alpha-1,6$ (Nigam \& Singh, 1995) tornando a molécula altamente ramificada conforme mostra a Figura 3. 


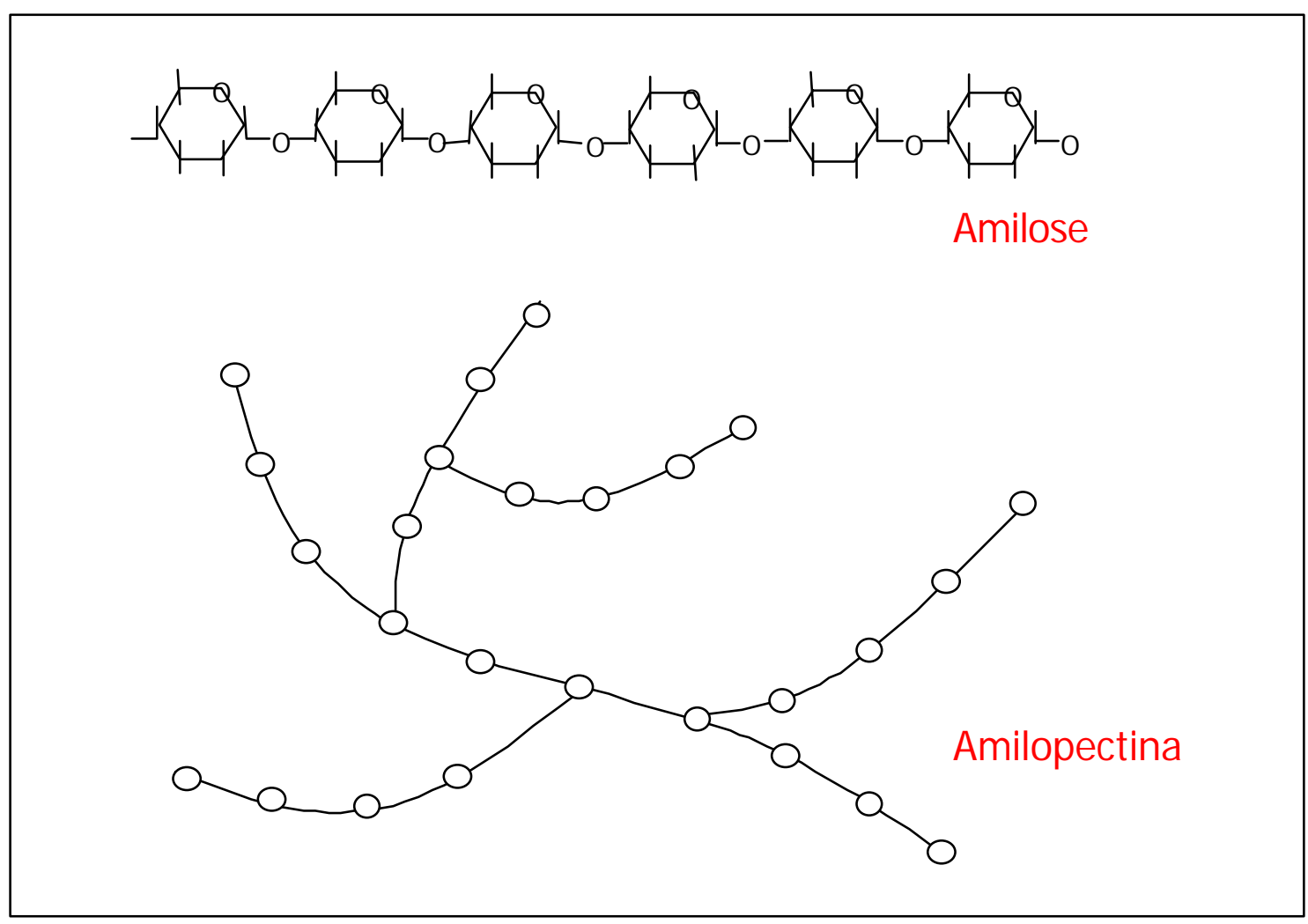

Figura 3 - Estruturas das cadeias componentes do amido: amilose e amilopectina.

Os teores de amilose e amilopectina variam conforme a espécie e a idade da fonte. O amido da mandioca contém aproximadamente $18 \%$ de amilose enquanto o de milho contém 25\% (Bobbio \& Bobbio, 1992). Os grânulos de amido da mandioca têm formato esférico, com diâmetro médio de $12 \mu \mathrm{m}$ (Valetudie et al., 1993).

No início do século XIX, Kirchhoff, um químico alemão, descobriu que a fervura de amido em solução ácida produzia uma substância doce (Dziedzic \& Kearsley, 1984). O primeiro avanço tecnológico significativo ocorreu em 1946, 
quando Dale e Langois patentearam o uso de enzimas disponíveis no mercado para a produção comercial de xaropes de milho (Nigam \& Singh, 1995), mas somente na década de 70 o consumo de xaropes em substituição à sacarose se tornou importante comercialmente (Maldonado \& Lopez, 1995).

O xarope de maltose é tradicionalmente obtido a partir da hidrólise ácida ou e/ou enzimática de amido de milho. Fontes de amido como o arroz e a mandioca, por exemplo, são produzidas em grandes quantidades no mundo e sua conversão a xarope de glicose deveria receber mais atenção (Kearsley \& Tabiri, 1979). Ainda hoje é muito restrito o número de publicações que descrevem a produção de xarope com fontes de amido diferentes do milho, principalmente por hidrólise direta (sem extração do amido).

A hidrólise ácida ainda é muito usada, porém o uso de enzimas traz muitas vantagens. Uma delas é que a especificidade das enzimas proporciona a obtenção de xaropes com propriedades químicas e físicas bem definidas. Outra vantagem é que a reação mais branda resulta em menos reações secundárias e menos escurecimento do produto final (Nigam \& Singh, 1995).

Em 1979, Aschengreen \& Nielsen compararam a hidrólise das féculas de mandioca e batata e dos amidos de trigo e de milho e concluíram que é possível obter xaropes de frutose semelhantes aos obtidos com amido de milho ou dextrose.

Lages \& Tannenbaum (1979) descreveram a produção de xarope de glicose a partir de fécula e farinha de mandioca com rendimento de $99 \%$, sendo que os sólidos não convertidos da farinha foram removidos e aproveitados para ração animal.

Para melhorar o rendimento de maltose Sato \& Park (1980), propuseram a utilização conjunta da $\beta$-amilase (soja) e da isoamilase, que romperiam as ligações $\alpha-1,6$, para a produção em larga escala de xarope de maltose a partir de amido isolado de milho. O uso enzimas desramificadoras também foi proposto por Slominska \& Starogardzka (1986) utilizando simultaneamente amilase maltogênica (B. stearothermophillus), pululanase e $\alpha$-amilase fúngica 
propiciando maior rendimento do xarope de maltose, a partir de amido de batata com $70-85 \%$ de maltose.

Industrialmente, o hidrolisado é obtido freqüentemente a partir do amido purificado, mas pelo seu elevado teor em alguns tubérculos e cereais, estes podem ser usados diretamente para eliminar a etapa de extração de amido. Porém, a economia na etapa de extração é parcialmente perdida por motivo das maiores dificuldades nas etapas de purificação (Berghofer \& Sarhaddar, 1988). Ghildyal at al (1989) compararam duas plantas de produção de xarope de frutose e concluíram que o uso de raspas de mandioca representa maiores custos de produção em relação ao amido da mandioca principalmente devido às complicações no processo.

Shaw \& Sheu (1992) desenvolveram um processo de obtenção direta e simultânea de xarope de maltose e de uma farinha com alto teor de proteína a partir de arroz, comprovando a eficiência da enzima desramificadora pululanase.

A hidrólise enzimática é geralmente feita em reatores em bateladas usando enzimas livres. Esse método apresenta algumas desvantagens devido aos longos períodos de reação, grande volume dos reatores e baixa utilização das enzimas. Sims \& Cheryan (1992) relataram a produção contínua de xarope de glicose com a utilização de ultrafiltração. O processo, segundo Gaouar et al. (1997b), não seria indicado para o xarope de maltose, pois implicaria emprego de elevadas temperaturas para controlar contaminações que destruiria a $\alpha$ amilase fúngica que é sensível a temperaturas maiores que $55^{\circ} \mathrm{C}$. Porém a produção contínua de xarope de alta maltose (40-60\%) foi descrita com sucesso por Gaouar et al. (1997a) com o uso da Maltogenase (exo- $\alpha$-amilase) por 6 horas a $65^{\circ} \mathrm{C}$. A produção de xarope com altíssimo conteúdo de maltose porém não foi possível devido à impossibilidade de uso de enzima desramificadora (pululanase ou isoamilase) que tem baixa resistência térmica.

O xarope de maltose que pode ser também produzido a partir de fécula de mandioca já vem sendo utilizado em cervejarias como substituto de adjuntos 
amiláceos e utilizado com sucesso na produção de cerveja conforme relatado por Venturini Filho \& Cereda (1998).

Conforme o processo utilizado, o xarope apresentará diferentes concentrações de maltose e grau de dextrose equivalente (DE) podendo ser classificado em três diferentes tipos como mostram a Tabela 2 e a Figura 4.



Figura 4 - Fluxograma de produção de xarope de maltose com diferentes composições.

Fonte: Maldonado \& Lopez (1995) 
Tabela 2. Composição dos diferentes tipos de xarope de maltose e sua dextrose Equivalente (DE).

\begin{tabular}{lccc}
\hline $\begin{array}{c}\text { Carboidratos } \\
(\%, \text { base seca) }\end{array}$ & $\begin{array}{c}\text { Xarope com alto teor } \\
\text { de maltose }\end{array}$ & $\begin{array}{c}\text { Xarope com extremo } \\
\text { teor de maltose }\end{array}$ & $\begin{array}{c}\text { Xarope de alta } \\
\text { conversão }\end{array}$ \\
\hline Glicose & $0,5-3,0$ & $1,0-3,0$ & $35,0-43,0$ \\
Maltose & $30,0-45,0$ & $70,0-85,0$ & $30,0-47,0$ \\
Maltotriose & $6,0-25,0$ & $8,0-21,0$ & $8,0-15,0$ \\
DE & $35-50$ & $45-60$ & $60-70$ \\
\hline
\end{tabular}

Fonte: Maldonado \& Lopez (1995); Saha \& Zeikus (1987)

Em virtude de suas características peculiares, o xarope de maltose é utilizado em fermentações, panificação, bebidas e confeitaria (Maldonado \& Lopez, 1995). Apresenta baixa higroscopicidade, sendo utilizado para o controle da atividade de água em alimentos (Gaouar et al. , 1997a e Shaw \& Sheu, 1992). Por suas características de baixa cristalização e resistência a temperaturas, é muito utilizado em geléias, compotas e sorvetes (Johnson, 1976; Nigam \& Singh; 1995 e Shaw \& Sheu, 1992). A maltose também é muito usada em balas moles para o controle da cristalização, umidade e manutenção da consistência (Johnson, 1976). Outra característica importante é seu efeito anti-séptico (Slominska \& Starogardzka, 1986) que possibilita sua utilização como veículo de transporte em vacinas, antibióticos e nutrientes intravenosos (Gaouar et al., 1997a). Além disso, o xarope com mais de $70 \%$ de maltose é usado pela indústria farmacêutica para a produção do adoçante maltiol (Gaouar et al., 1997a). 


\section{MATERIAL E MÉTODOS}

\subsection{Material}

\subsubsection{Matéria prima}

As raízes de mandioca (Manihot esculenta Crantz), da variedade "pão amarela", utilizadas no experimento $(100 \mathrm{~kg})$ foram adquiridas de um mesmo lote de um pequeno produtor do município de Piracicaba, Estado de São Paulo.

\subsubsection{Preparo das raspas de mandioca}

Foram utilizados $50 \mathrm{~kg}$ de raízes descascadas manualmente para a retirada película externa. Foram, em seguida, lavadas em água e trituradas em moedor de cana-de-açúcar. As raízes trituradas foram colocadas em bandejas de alumínio e secas em estufa de circulação forçada de ar a $60^{\circ} \mathrm{C}$ por 48 horas.

\subsubsection{Preparo da Puba}

Foram utilizados $50 \mathrm{~kg}$ de raízes descascadas manualmente para a retirada da película externa. As raízes descascadas foram lavadas em água e cortadas em pedaços de aproximadamente 5 a $7 \mathrm{~cm}$ e acondicionadas em recipientes plásticos com água na proporção de 1 parte de mandioca para 2 
partes de água. Concluída a fermentação natural àtemperatura ambiente (25 $28^{\circ} \mathrm{C}$ ) durante 4 dias (96 horas), as mandiocas foram colocadas em sacos de algodão e espremidas para a drenagem da água. As raízes fermentadas foram colocadas em bandejas de alumínio e secas em estufa de circulação forçada de ar a $60^{\circ} \mathrm{C}$ por 48 horas.

\subsubsection{Enzimas}

Foram utilizadas as enzimas $\alpha$-amilase bacteriana (endo-amilase) CANALPHA 5000P derivada do Bacillus subtilis com atividade de 4.900 .000 BBA u/g na proporção de $0,033 \%$ em peso de matéria seca e a $\alpha$-amilase fúngica (maltogenase) BIOFERM $\mathrm{P}$ derivada do Aspergillus oryzae com atividade de 1.550.000 FAA u/g na proporção de 0,033\% em peso de matéria seca. Ambas enzimas foram cedidas pela empresa Quest na forma de pó. Para a utilização as enzimas em pó foram diluídas em água destilada na proporção de $1 \mathrm{~g} / 100 \mathrm{ml}$.

\subsection{Métodos}

\subsubsection{Produção dos hidrolisados}

O processo de obtenção do xarope de maltose a partir da mandioca e da puba obedeceu ao fluxograma da Figura 5. 


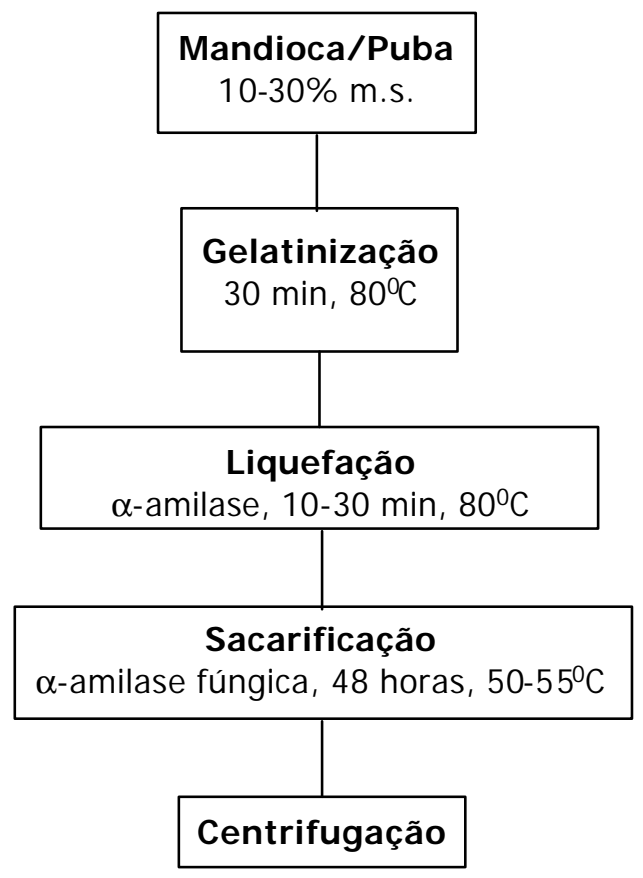

Figura 5 - Fluxograma de produção dos hidrolisados de mandioca e puba.

\subsubsection{Preparação das amostras}

Todas as quantidades utilizadas foram pesadas em balança semianalítica.

Trinta, 60 e $90 \mathrm{~g}$ de mandioca ou puba foram colocados separadamente em Erlenmeyer de $500 \mathrm{ml}$ contendo respectivamente 270, 240 e $210 \mathrm{~g}$ de água destilada para totalizar $300 \mathrm{~g}$ e concentrações de sólidos de 10, 20 e 30\%. As amostras foram codificadas conforme a Figura 6. 


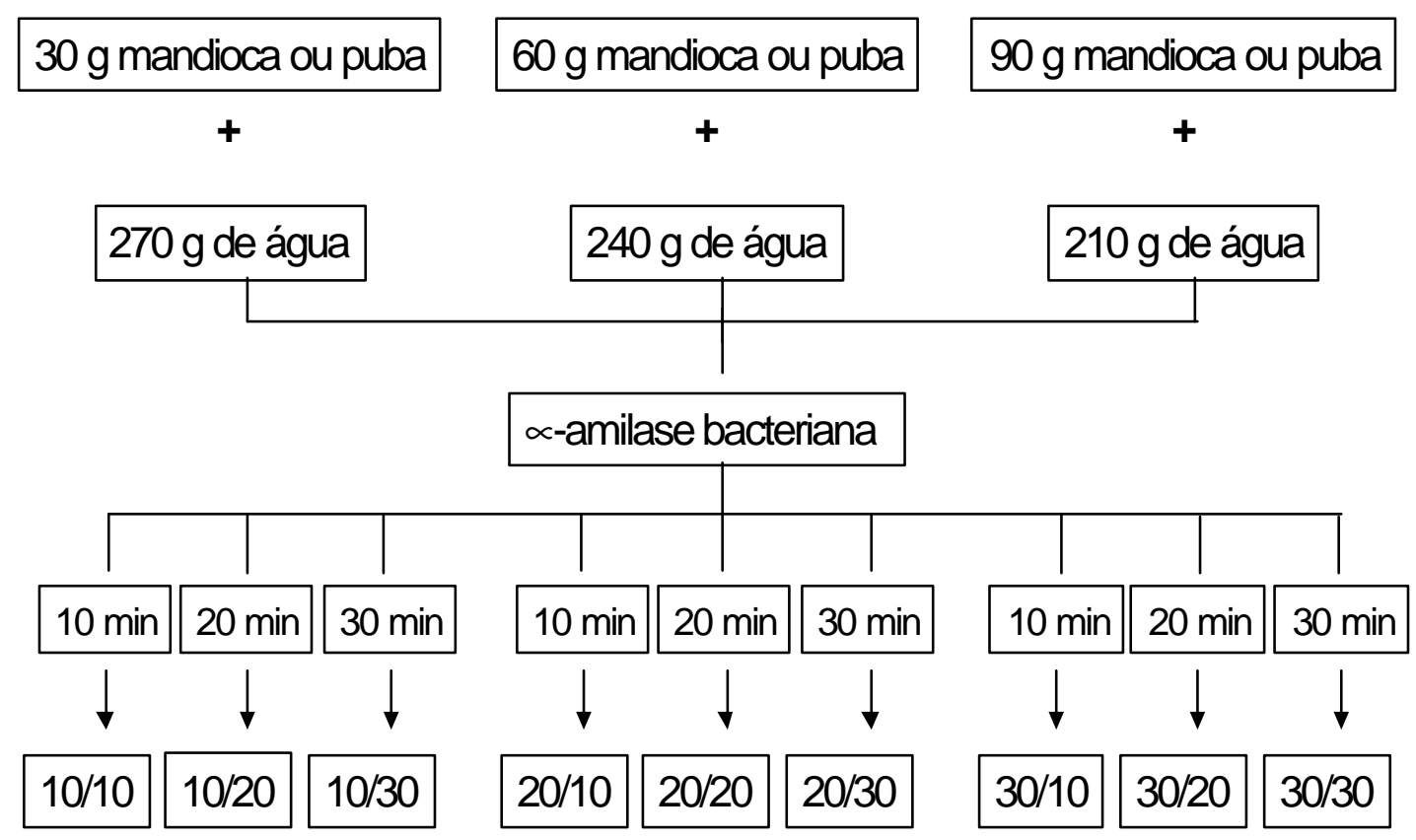

Figura 6 - Esquema de codificação das amostras.

Cada código foi formado por dois números separados por uma barra. $\mathrm{O}$ $1^{\circ}$ número se refere à concentração de sólidos na amostra como mostra a Figura 2. $\mathrm{O} 2^{0}$ número se refere ao tempo de exposição àenzima $\alpha$-amilase bacteriana durante a liquefação em minutos (10, 20 ou 30).

Dessa forma foram obtidos 9 tratamentos para a mandioca e 9 tratamentos para a puba. Cada bloco foi composto pelos 9 tratamentos distintos da mandioca ou da puba e realizados separadamente delineando deste modo os blocos em função do tempo.

Os ensaios de cada bloco foram repetidos 5 vezes obtendo-se 90 amostras no total. 


\subsubsection{Gelatinização}

Os frascos com $300 \mathrm{~g}$ foram colocados em banho com circulação de água a $80^{\circ} \mathrm{C}$ por 30 minutos. O conteúdo dos frascos foi constantemente homogeneizado (manualmente) para a gelatinização da fécula.

\subsubsection{Liquefação}

Após a gelatinização adicionou-se em cada frasco a enzima $\alpha$-amilase bacteriana na proporção de $0,033 \%(p / p)$ em relação àmatéria seca. Os frascos foram mantidos a $80{ }^{\circ} \mathrm{C}$ por 10,20 ou 30 minutos (conforme Figura 6). Em seguida os frascos foram resfriados em banho gelado até $50^{\circ} \mathrm{C}$.

\subsubsection{Sacarificação}

Adicionou-se $\alpha$-amilase fúngica, na proporção de $0,033 \%$, ao substrato liquefeito e resfriado. Em seguida os frascos foram fechados com filme plástico e incubados a temperatura de $50-55^{\circ} \mathrm{C}$ por 48 horas em banho com agitador rotativo a aproximadamente $100 \mathrm{rpm}$.

\subsubsection{Centrifugação}

Após a sacarificação o conteúdo dos frascos foi centrifugado a 3000 rpm por 20 minutos a temperatura de $20^{\circ} \mathrm{C}$ para a separação dos resíduos sólidos restantes. 


\subsubsection{Análise dos hidrolisados}

\subsubsection{Matéria seca}

Após a liquefação foi retirada uma alíquota de $2 \mathrm{~g}$ de cada tratamento para a quantificação de matéria seca. As amostras foram secas em estufa a $105^{\circ} \mathrm{C}$ por 24 horas e pesadas em balança analítica (Association of Official Analytical Chemists, 1980).

\subsubsection{Dextrose equivalente (DE)}

Foram retiradas alíquotas de $3 \mathrm{~g}$ de cada tratamento nos tempos $0,4,8$, 12, 22, 28, 36, 48 horas para a determinação de açúcares redutores. As alíquotas foram diluídas com $70 \mathrm{ml}$ de água destilada a $45^{\circ} \mathrm{C}$ e filtradas em papel de filtro, completando-se o volume para $100 \mathrm{~mL}$. As alíquotas ainda foram diluídas mais uma vez na proporção de 25:100 determinando-se em seguida, os açúcares redutores em $1 \mathrm{ml}$ da alíquota diluída. Os açúcares redutores foram determinados pelo método do ácido dinitrosalicílico (DNS) (Miller, 1959). Para a quantificação dos açúcares redutores construiu-se uma curva de calibração de glicose lendo-se a absorbância em espectrofotômetro a 540nm. O DE foi calculado conforme a fórmula (1) (Pontoh \& Low, 1995).

$$
\mathrm{DE}=\frac{\text { Açúcares redutores }(\mathrm{g})}{\text { Sólidos totais }(\mathrm{g})} \times 100
$$




\subsubsection{Eficiência de hidrólise}

O resíduo centrifugado conforme item 3.2.1.5 foi seco em estufa de circulação forçada de ar a $105^{\circ} \mathrm{C}$ por 24 horas para cálculo da quantidade de sólidos iniciais que foram solubilizados. A eficiência da hidrólise foi calculada pela fórmula (2).

$\%$ Eficiência de hidrólise $=\frac{\text { Sólidos iniciais }(\mathrm{g})-\text { Sólidos finais }(\mathrm{g})}{\text { Sólidos iniciais }(\mathrm{g})} \times 100$

\subsubsection{Análise cromatográfica}

O líquido sobrenadante da centrifugação da $5^{\mathrm{a}}$ repetição foi clarificado com sulfato de zinco e hidróxido de bário (Villela et al., 1973) para a realização da análise cromatográfica. O líquido clarificado foi acondicionado em frascos de vidro e congelados $\mathrm{a} \approx-10^{\circ} \mathrm{C}$ para a preservação das amostras.

As determinações dos teores de glicose e maltose do hidrolisado foram efetuadas mediante cromatografia líquida de alta eficiência (CLAE) em cromatógrafo iônico DIONEX DX-300, equipado com coluna Carbopac-1, a $25^{\circ} \mathrm{C}$, com detector de amperometria de pulso com eletrodo de ouro, usando-se $\mathrm{NaOH} 100 \mathrm{mM}$ como eluente a um fluxo de $0,9 \mathrm{~mL}$ por minuto.

Os resultados foram expressos em gramas por $100 \mathrm{ml}$ (Anexo A) e transformados para porcentagem de maltose e glicose nos açúcares totais os quais foram determinados pelo método de antrona (Bacila,1960). 


\subsubsection{Balanço de massa}

O balanço de massa foi calculado para cada tratamento para que pudessem ser comparados os índices de produção de maltose e glicose de cada um deles a partir da mesma matéria prima. Para isso foram simulados cálculos a partir de $100 \mathrm{~kg}$ de mandioca fresca. O rendimento de raspas secas e puba seca foi calculado a partir dos dados apresentados no item 4.1.1. Após a centrifugação o conteúdo de liquido sobrenadante e precipitados foram pesados. O precipitado foi seco em estufa como descrito no item 3.2.2.3. O líquido sobrenadante foi clarificado sendo quantificados os açúcares totais, a maltose e a glicose como citado no item 3.2.2.4.

\subsubsection{Delineamento experimental}

O experimento foi montado com delineamento em blocos casualizados com 9 tratamentos para a mandioca e 9 tratamentos para a puba. Os blocos foram delimitados em função do tempo. Foram feitas 5 repetições para cada matéria-prima, totalizando 90 ensaios.

Foi efetuado teste $f$ e teste de Tuckey de comparação de médias nas análises estatísticas ao nível de $5 \%$ de significância. Para o cálculo das análises estatísticas foi usado o programa SAS System for Windows 6.11. 


\section{RESULTADOS E DISCUSSÃO}

\subsection{Produção dos hidrolisados}

\subsubsection{Preparo de matéria-prima}

Os ensaios preliminares realizados para indicar a melhor forma de utilização da matéria-prima, como mandioca seca natural, ralada, picada e triturada, indicaram que não houve diferença quanto aos valores de DE obtidos e portanto foi escolhida a mandioca triturada, processo que se mostrou de mais fácil execução no laboratório para os experimentos posteriores de hidrólise. Da secagem de $50 \mathrm{~kg}$ de raízes após o descascamento foram obtidas $14,1 \mathrm{~kg}$ de raspas secas correspondendo a rendimento de $28,2 \%$; fermentando $50 \mathrm{~kg}$ de raízes foram obtidas $14,26 \mathrm{~kg}$ de massa de puba seca que corresponde ao rendimento de $28,5 \%$ indicando que não houve perdas de material devido à fermentação da mandioca.

A secagem foi necessária para que permitisse a utilização do mesmo lote de raízes durante todos experimentos. Além disso, Berghofer \& Sarhaddar (1988) consideraram a secagem como um processo importante porque permite o uso de raspas de mandioca seca e a continuidade da produção durante o ano todo e não apenas na época de colheita. O mesmo processo de secagem foi adotado para a puba para mantê-la com características semelhantes. 


\subsubsection{Concentração de sólidos}

O teor de matéria seca do concentrado que apresentou viscosidade que possibilitasse melhores facilidades de operação foi de $20 \%$ embora, industrialmente, opere-se entre 30 e 40\% (Maldonado \& Lopez, 1995; Saha \& Zeikus, 1987). A elevada viscosidade das amostras com estas concentrações, nas condições de laboratório, impediu a sua completa homogeneização. Embora o teor de $30 \%$ de matéria seca tenha sido a concentração máxima conseguida, o manuseio foi dificultado devido à alta viscosidade da amostra, principalmente durante a gelatinização. As amostras com $10 \%$ de matéria seca exigiriam maior dispêndio de energia no processo de concentração do hidrolisado devido ànecessidade de se evaporar maior quantidade de água.

Aschengreen \& Nielsen (1979) afirmaram que apesar de ser normal a utilização de concentrações acima de 30\%, a liquefação ocorre suavemente e a sacarificação apresenta melhor rendimento em relação ao DE com concentrações de $30 \%$.

\subsubsection{Gelatinização}

A gelatinização consiste em aquecer com água os grânulos de amido a fim de hidratar, intumescer e rompê-los para liberar a amilose e a amilopectina.

$O$ amido de cada espécie vegetal apresenta morfologia e propriedades físico-químicas próprias e entre elas a temperatura de gelatinização. O intervalo de temperatura de gelatinização do amido de mandioca está entre $58-75^{\circ} \mathrm{C}$. (Bobbio \& Bobbio, 1992 e Hoover, 2001) e o da puba entre $80-85^{\circ} \mathrm{C}$ (Mendes, 1992). Essas temperaturas indicam, num primeiro momento, que se deva utilizar a mandioca uma vez que temperaturas menores podem significar economia de energia. Porém a puba forma uma massa e na mandioca há uma concorrência das fibras com os grânulos de amido pela água com formação de 
grumos que podem dificultar o processo e o acesso das enzimas da etapa de sacarificação ao interior dos grumos (Mendes, 1992).

Durante o aquecimento, a gelatinização foi percebida visualmente quando as soluções se tornaram translúcidas e muito viscosas devido à hidratação dos grânulos de amido. Exceções foram as amostras com 10\% de matéria seca uma vez que o elevado teor de hidratação mascarou a alteração visual da viscosidade.

\subsubsection{Liquefação}

A liquefação que tem como objetivo "quebrar" as moléculas de amido para reduzir a viscosidade e auxiliar a ação da enzima a ser usada posteriormente.

Os períodos de liquefação utilizados neste trabalho foram baseados na avaliação visual e através das especificações do preparado enzímico comercial da $\alpha$-amilase bacteriana utilizado. Esta enzima apresenta temperatura ótima de atividade a $80^{\circ} \mathrm{C}$ e retém mais de $80 \%$ de atividade entre $55-85^{\circ} \mathrm{C}$ (catálogo Quest).

A liquefação das amostras foi percebida imediatamente após a adição da enzima pela diminuição drástica da viscosidade em todas as amostras. O tempo máximo de 30 minutos foi definido pela curva de estabilidade da enzima que após este período, à temperatura de $75^{\circ} \mathrm{C}$, apresenta apenas $40 \%$ da atividade inicial (catálogo Quest). Pontoh \& Low (1995) também usaram tempo de liquefação de 30 minutos para amido de mandioca e de milho que é considerado baixo quando comparada ao usado industrialmente que pode variar entre 60 e 90 minutos. Segundo esses autores a alta eficiência da agitação em escala laboratorial permite reduzir o tempo de liquefação. 
Os aspectos visuais de consistência das amostras submetidas a diferentes períodos de liquefação foram semelhantes tanto na puba como na mandioca.

Com o objetivo de isolar os efeitos das duas enzimas, tentou-se, após a liquefação, inativar a $\alpha$-amilase bacteriana antes da adição $\alpha$-amilase fúngica. No entanto, o uso de solução ácida de $\mathrm{HCl} 1 \mathrm{~N}$ foi ineficiente para abaixar o pH. Isso pode ter ocorrido por causa da formação de uma solução tampão, conforme relatado por Venturini Filho \& Cereda (1998). Os autores verificaram que o hidrolisado de mandioca tem $\mathrm{pH}$ maior e igual acidez em relação ao hidrolisado de milho e sugeriram que o maior conteúdo de cinzas no hidrolisado de mandioca favorece a formação de solução tampão.

Como não foi possível inativar a enzima por desnaturação (redução do $\mathrm{pH}$ ) resfriou-se rapidamente a $50^{\circ} \mathrm{C}$, em banho com gelo, para paralisar a ação da $\alpha$-amilase bacteriana.

\subsubsection{Sacarificação}

Durante o período de sacarificação, que tem como objetivo quebrar o amido liquefeito em moléculas de maltose, foram observadas modificações de cor e odor nas amostras durante o período de 48 horas.

Enquanto as amostras de mandioca escureceram e apresentaram coloração amarelada e odor desagradável ao final das 48 horas de incubação, as amostras de puba permaneceram com a coloração esbranquiçada inicial e mantiveram odor agradável do início ao fim. As amostras de puba apresentaram consistência mais homogênea e pastosa do que as amostras de mandioca. 


\subsubsection{Separação de sólidos dos hidrolisados}

Tentativas para filtrar os hidrolisados não foram bem sucedidas em virtude do grande volume de sólidos remanescentes, sendo por isso centrifugados.

As amostras centrifugadas de mandioca formaram uma suspensão que dificultou a separação do material sólido do sobrenadante. As amostras centrifugadas de puba formaram um precipitado denso e bem separado do sobrenadante.

Após a separação, ainda foi possível notar diferenças na coloração e odor das amostras de mandioca e puba como descrito no item 4.1.5. A coloração amarelada e o odor desagradável nas amostras de mandioca podem resultar em maiores dificuldades nas etapas posteriores de purificação e concentração das amostras.

\subsection{Composição do xarope}

\subsubsection{Matéria seca}

As quantidades de matéria seca das amostras no início da sacarificação foram determinadas para o posterior cálculo da DE e da eficiência de hidrólise e estão apresentadas na Tabela 3. 
Tabela 3. Conteúdo de sólidos nas amostras de mandioca.

\begin{tabular}{c|cc}
\hline \multirow{2}{*}{$\begin{array}{c}\text { Amostra } \\
\text { (concentração/tempo) }\end{array}$} & \multicolumn{2}{|c}{ Sólidos (\%) } \\
\cline { 2 - 3 } & Mandioca & Puba \\
\hline $10 / 10$ & 9,5 & 9,8 \\
$10 / 20$ & 9,7 & 9,2 \\
$10 / 30$ & 10,0 & 9,9 \\
$20 / 10$ & 19,5 & 19,6 \\
$20 / 20$ & 19,7 & 19,6 \\
$20 / 30$ & 19,3 & 19,3 \\
$30 / 10$ & 28,5 & 29,6 \\
$30 / 20$ & 28,8 & 29,7 \\
$30 / 30$ & 29,1 & 29,9 \\
\hline
\end{tabular}

A porcentagem de sólidos das amostras no início da sacarificação apresentou uma pequena diferença em relação æ̀̀ quantidades prédeterminadas e que foram apresentadas na Figura 6. Provavelmente esta pequena diferença se deve a umidade na matéria prima inicial. Por essa razão esses resultados serão utilizados no calculo dos valores $\mathrm{DE}$.

\subsubsection{Dextrose Equivalente (DE)}

\subsubsection{Mandioca}

Os valores de DE da mandioca antes da liquefação variaram de 0,6 a 0,9 . Esses valores estão dentro da faixa de 0,1 a $2,8 \mathrm{~g}$ de açúcares redutores por $100 \mathrm{~g}$ de mandioca seca relatado por Menezes (1980). Gorinstein \& Lii (1992) relataram 0,08 g/100 g de açúcares redutores em amostras de mandioca crua. Apesar da diferença ser de aproximadamente 10 vezes, o valor de 0,9 
ainda é bastante baixo. Os valores de DE após a liquefação estão mostrados na Tabela 4.

Os resultados mostraram que não houve diferenças significativas nos valores de $\mathrm{DE}$ ao final da liquefação entre nenhum dos tratamentos. Houve apenas uma tendência das amostras de concentração 10\% apresentarem um DE mais baixo em todos os experimentos.

Tabela 4. Dextrose equivalente nas amostras de mandioca após a liquefação.

\begin{tabular}{cc}
\hline Tratamentos (conc./tempo) & DE (média) \\
\hline $10 / 10$ & 24,4 a \\
$10 / 20$ & 22,0 a \\
$10 / 30$ & 21,3 a \\
$20 / 10$ & 29,4 a \\
$20 / 20$ & 30,3 a \\
$20 / 30$ & 28,8 a \\
$30 / 10$ & 28,5 a \\
$30 / 20$ & 30,4 a \\
$30 / 30$ & 29,1 a \\
\hline
\end{tabular}

*Valores acompanhados com a mesma letra não são diferentes ao nível de $5 \%$ de significância.

Kearsley \& Tabiri (1979) obtiveram hidrolisados com DE 17 trabalhando com mandioca in natura, $6 \%$ de sólidos durante 1 hora de incubação com $\alpha$ amilase bacteriana. No presente trabalho amostras com concentrações de sólidos maiores (10, 20 e 30\%) foram submetidas à ação da enzima por tempos menores (de 10 a 30 minutos) e obtendo-se valores de DE mais elevados.

O tempo de ação da enzima $\alpha$-amilase bacteriana também não influenciou os índices de sacarificação, pois esses valores não foram significativamente diferentes ao nível de $5 \%$ de significância (Tabela 4).

As curvas obtidas durante as 48 horas sacarificação estão apresentadas na Figura 7. 


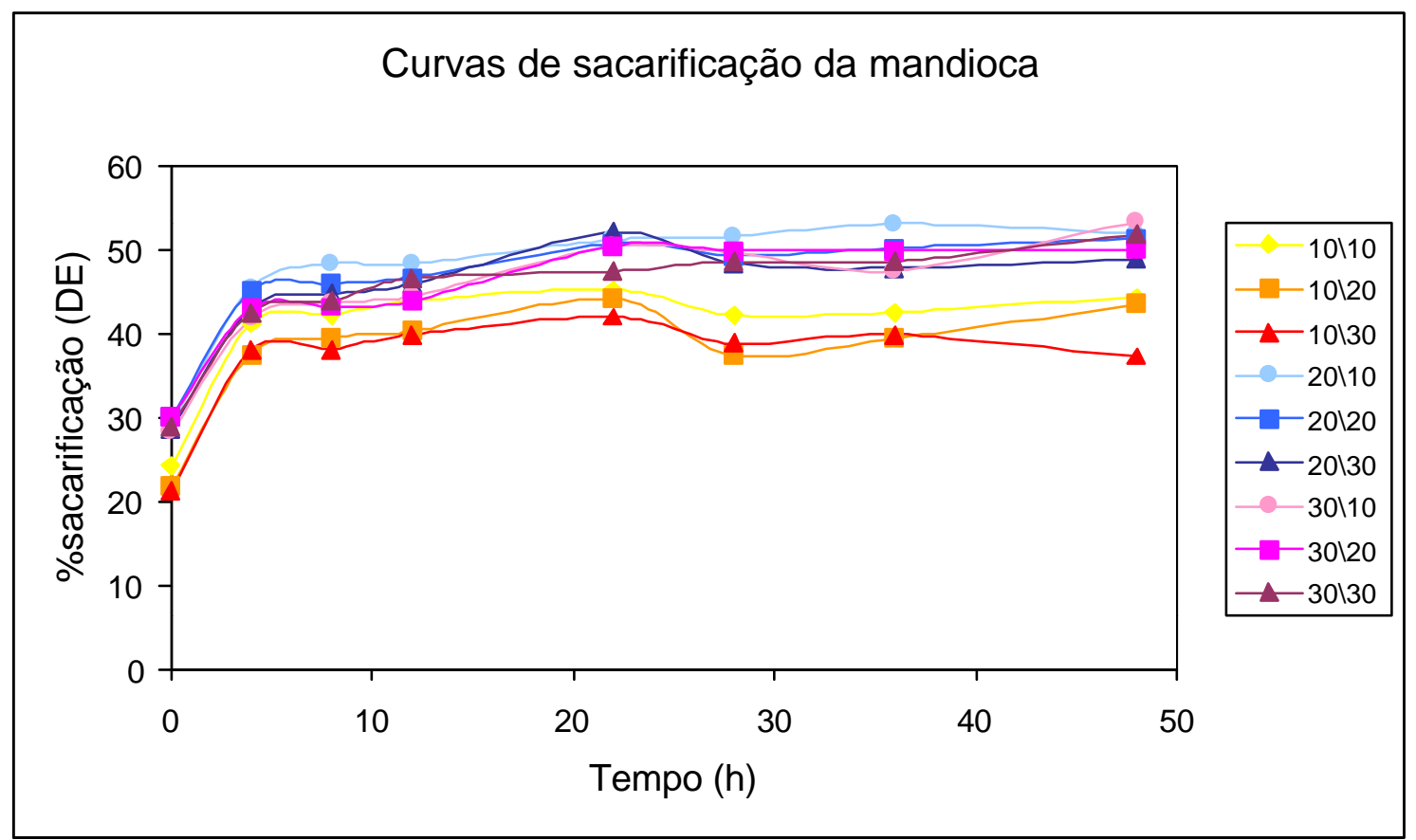

Figura 7 - Curvas de sacarificação das amostras de mandioca.

O aumento mais significativo nos valores de DE ocorreu durante as primeiras 4 horas da sacarificação e foi percebido em todos os tratamentos. Verifica-se também que para os tratamentos com concentração de $10 \%$ de sólidos os valores de DE não aumentaram no decorrer da sacarificação, enquanto que para os demais, os valores de DE continuaram aumentando até 48 horas. Estatisticamente não houve diferença significativa entre os tempos de tratamento após 4 horas, exceto para os tratamentos 30/10 no qual ainda aparecem diferenças significativas até 22 horas de sacarificação. Esses resultados podem indicar que não é necessário, pelo menos em escala de laboratório, que a sacarificação seja prolongada por 48 horas. A partir de 22 horas nenhum dos tratamentos apresentou diferenças significativas, ou seja, a partir de 22 horas rão houve aumento significativo nos valores de DE (Anexo B). 
Durante a sacarificação todas as amostras se comportaram de forma semelhante. As amostras de concentração 10\% apresentaram resultados de DE mais baixos do que os demais mas todos os tratamentos mostraram resultados muito próximos.

A Tabela 5 mostra alguns dados da Figura 7 com a análise estatística entre os tratamentos.

Tabela 5. Influência da concentração de sólidos da mandioca e do tempo de sacarificação nos índices de DE.

\begin{tabular}{c|ccc}
\hline \multirow{2}{*}{$\begin{array}{c}\text { Tratamentos } \\
\text { conc/tempo }\end{array}$} & \multicolumn{4}{|c}{ Tempo de sacarificação } \\
\cline { 2 - 5 } & 12 horas & 28 horas & 48 horas \\
\hline $10 / 10$ & $44,1 \mathrm{a}$ & $42,3 \mathrm{abc}$ & $44,5 \mathrm{ab}$ \\
$10 / 20$ & $40,5 \mathrm{a}$ & $37,5 \mathrm{c}$ & $43,7 \mathrm{ab}$ \\
$10 / 30$ & $40,1 \mathrm{a}$ & $38,9 \mathrm{bc}$ & $37,5 \mathrm{~b}$ \\
$20 / 10$ & $48,4 \mathrm{a}$ & $51,7 \mathrm{a}$ & $52,1 \mathrm{a}$ \\
$20 / 20$ & $46,9 \mathrm{a}$ & $49,4 \mathrm{ab}$ & $51,6 \mathrm{a}$ \\
$20 / 30$ & $46,1 \mathrm{a}$ & $48,5 \mathrm{abc}$ & $49,1 \mathrm{a}$ \\
$30 / 10$ & $44,7 \mathrm{a}$ & $49,9 \mathrm{ab}$ & $53,5 \mathrm{a}$ \\
$30 / 20$ & $44,0 \mathrm{a}$ & $50,0 \mathrm{ab}$ & $50,3 \mathrm{a}$ \\
$30 / 30$ & $46,7 \mathrm{a}$ & $48,8 \mathrm{ab}$ & $51,9 \mathrm{a}$ \\
\hline
\end{tabular}

"Valores acompanhados com a mesma letra não são diferentes ao nível de $5 \%$ de significância.

Observou-se que não houve diferença significativa entre as médias de DE entre os tratamentos até 12 horas de sacarificação. Em 28 horas de sacarificação as amostras com $10 \%$ de sólidos apresentaram valores de $\mathrm{DE}$ inferiores às amostras com 20 e 30\%. Embora haja diferenças significativas entre médias de DE de diversos tratamentos, não se observou um padrão que relacione os teores de sólidos e o tempo de sacarificação com os índices de DE. Em 48 horas os tratamentos com concentrações de $20 \%$ e $30 \%$ apresentaram valores de DE mais elevados e o tratamento 10/30 diferiu 
significativamente dos demais com concentrações mais elevadas de sólidos. Com 12 e 28 horas de sacarificação o tratamento 20/10 propiciou maiores valores de DE enquanto com 48 horas a combinação 30/10 resultou em maior valor.

\subsubsection{Puba}

O DE da puba após a liquefação aumentou na medida que aumentou a concentração de sólidos. Por sua vez o aumento do tempo de liquefação não influenciou significativamente o índice de sacarificação.

Tabela 6. Dextrose equivalente nas amostras de puba após a liquefação.

\begin{tabular}{cc}
\hline Tratamentos (conc./tempo) & DE (média) \\
\hline $10 / 10$ & $0,5 \mathrm{~d}$ \\
$10 / 20$ & $0,6 \mathrm{~d}$ \\
$10 / 30$ & $0,9 \mathrm{~d}$ \\
$20 / 10$ & $18,7 \mathrm{~b}$ \\
$20 / 20$ & $13,8 \mathrm{bc}$ \\
$20 / 30$ & $08,8 \mathrm{c}$ \\
$30 / 10$ & $29,1 \mathrm{a}$ \\
$30 / 20$ & $27,8 \mathrm{a}$ \\
$30 / 30$ & $30,3 \mathrm{a}$ \\
\hline "Valores acompanhados com a mesma letra não são diferentes ao nível de $5 \%$ de \\
significância.
\end{tabular}

Observando comparativamente os resultados da puba (Tabela 6) com os da mandioca (Tabela 4) pode-se notar que os valores são semelhantes para a concentração $30 \%$ mas os valores de DE da puba são bem mais baixos do que os da mandioca nas concentrações 10 e $20 \%$ de sólidos. Essa diferença pode 
ser explicada pelo consumo de glicose durante a fermentação para produção da puba e também a $\alpha$-amilase bacteriana não teria completado sua ação.

As curvas da sacarificação das amostras de puba com a $\alpha$-amilase fúngica são mostradas na Figura 8 notando-se que os tratamentos com concentração de sólidos de 10\% apresentaram valores de DE bem mais baixos que os demais mesmo quando comparados aos resultados da mandioca (Figura 7). De modo geral as amostras com $30 \%$ de sólidos apresentaram valores de DE mais elevados.



Figura 8 - Curvas de sacarificação das amostras de puba.

Houve, como para os tratamentos da mandioca, um aumento acentuado dos valores de DE nas primeiras 4 horas de sacarificação. $O$ aumento nos valores de DE da puba apresentaram um crescimento maior no tempo do que 
as curvas da mandioca (Figura7). As análises estatísticas (Anexo C) para cada tratamento em relação ao tempo de sacarificação mostraram que não houve diferenças significativas. Apenas o tratamento 30/20 mostrou diferença significativa até 36 horas. Os resultados dos outros tratamentos não foram diferentes significativamente a partir de 4 ou 8 horas (Anexo C).

As análises estatísticas comparando os tratamentos em diferentes tempos de sacarificação (dados da Figura 8) estão apresentadas na Tabela 7.

Tabela 7 - Influência da concentração de sólidos da puba e do tempo de sacarificação nos índices de DE.

\begin{tabular}{c|cccc}
\hline \multirow{2}{*}{$\begin{array}{c}\text { Tratamentos } \\
\text { conc./tempo }\end{array}$} & \multicolumn{4}{|c}{ Tempo de sacarificação } \\
\cline { 2 - 5 } & 12 horas & 28 horas & 48 horas \\
\hline $10 / 10$ & $17,0 \mathrm{~b}$ & $21,2 \mathrm{c}$ & $22,4 \mathrm{c}$ \\
$10 / 20$ & $16,5 \mathrm{~b}$ & $21,6 \mathrm{c}$ & $20,7 \mathrm{c}$ \\
$10 / 30$ & $14,6 \mathrm{~b}$ & $17,4 \mathrm{c}$ & $19,0 \mathrm{c}$ \\
$20 / 10$ & $44,8 \mathrm{a}$ & $45,5 \mathrm{ab}$ & $50,3 \mathrm{ab}$ \\
$20 / 20$ & $42,3 \mathrm{a}$ & $47,2 \mathrm{ab}$ & $48,6 \mathrm{ab}$ \\
$20 / 30$ & $37,5 \mathrm{a}$ & $42,8 \mathrm{~b}$ & $43,5 \mathrm{~b}$ \\
$30 / 10$ & $46,3 \mathrm{a}$ & $51,8 \mathrm{a}$ & $55,1 \mathrm{a}$ \\
$30 / 20$ & $46,5 \mathrm{a}$ & $49,8 \mathrm{ab}$ & $56,9 \mathrm{a}$ \\
$30 / 30$ & $41,9 \mathrm{a}$ & $47,5 \mathrm{ab}$ & $53,3 \mathrm{ab}$ \\
\hline
\end{tabular}

"Valores acompanhados com a mesma letra não são diferentes ao nível de $5 \%$ de significância.

Pode-se afirmar que os tratamentos com concentração $10 \%$ de sólidos apresentaram DE significativamente mais baixos do que todos os demais durante todo período de sacarificação. Após 12 horas as amostras com 20 e $30 \%$ de sólidos ainda não apresentaram diferenças significativas mas após 28 horas as diferenças puderam ser observadas sendo que as amostras com $30 \%$ de sólidos apresentaram DE mais elevados. De modo geral os tratamentos com maiores concentrações de sólidos apresentaram valores mais elevados de DE. 
Apesar de que no início da sacarificação os tratamentos com puba apresentaram DE mais baixos do que os tratamentos com a mandioca, após 48 horas os valores de DE das amostras com puba foram mais elevados do que os tratamentos com a mandioca, principalmente as amostras com concentração de $30 \%$ de sólidos. Para a puba, o tatamento $30 / 20$ apresentou os mais altos resultados de DE. Além disso, assim como para a mandioca, houve uma tendência de aumento de DE até 48 horas indicando ainda a ação da enzima.

Os resultados de DE das amostras, tanto da mandioca quanto da puba, exceto aqueles obtidos com concentração $10 \%$ da puba, foram mais elevados quando comparados com resultados obtidos por Goering et al. (1980) que atingiu DE 40 após 36 horas de sacarificação usando amido de cevada.

\subsubsection{Perfil de açúcares}

Os tratamentos da mandioca mostraram de modo geral tendência de apresentar teores mais elevados de maltose se comparados aos mesmos tratamentos da puba. Porém, apresentaram também maior conteúdo de glicose. Os resultados estão apresentados na Tabela 8. 
Tabela 8. Perfil de açúcares (em base seca) e DE dos tratamentos de mandioca e puba.

\begin{tabular}{c|ccc|ccc}
\hline Tratamentos & \multicolumn{3}{|c|}{ Mandioca } & \multicolumn{3}{c}{ Puba } \\
\cline { 2 - 7 } (conc./tempo) & DE & \%Glicose & \%Maltose & DE & \%Glicose & \%Maltose \\
\hline $10 / 10$ & 44,5 & - & 49,9 & 22,4 & - & 30,7 \\
$10 / 20$ & 43,7 & - & 39,5 & 20,7 & 5,1 & 36,9 \\
$10 / 30$ & 37,5 & - & 43,5 & 19,0 & - & 28,8 \\
$20 / 10$ & 52,1 & 7,6 & 45,1 & 50,3 & 2,8 & 43,9 \\
$20 / 20$ & 51,6 & 6,6 & 49,2 & 48,6 & 2,5 & 47,1 \\
$20 / 30$ & 49,1 & 3,4 & 61,3 & 43,5 & 2,6 & 37,4 \\
$30 / 10$ & 53,5 & 10,7 & 43,5 & 55,1 & 6,0 & 45,4 \\
$30 / 20$ & 50,3 & 10,2 & 49,1 & 56,9 & 5,0 & 52,3 \\
$30 / 30$ & 51,9 & 11,3 & 52,5 & 53,3 & 4,7 & 43,0 \\
\hline
\end{tabular}

* Os valores de DE expressos nesta tabela se referem apenas a quinta repetição do experimento no qual foi feita a análise de açúcares.

Verifica-se que os teores de maltose nos hidrolisados de mandioca aumentaram com o aumento da concentração de sólidos até alcançar $20 \%$ e aumentaram também com o aumento do tempo de exposição da $\alpha$-amilase bacteriana, até atingir 30 minutos. O maior valor de maltose foi de $61,3 \%$ obtido com a combinação concentração/tempo 20/30. Os teores de glicose foram bem inferiores aos da maltose e só foram detectados nos hidrolisados de mandioca a partir de $20 \%$ sólidos. O valor máximo de glicose foi obtido no tratamento $30 / 30$ com $11,3 \%$, cerca de 4,6 vezes inferior ao teor de maltose. Os teores de maltose nos hidrolisados de puba foram inferiores aos da mandioca e, de modo geral tenderam a aumentar com o aumento da concentração de sólidos. O maior valor foi alcançado no binômio concentração/tempo de 30/20 com 52,3\% de maltose. Os teores de glicose nos hidrolisados de puba também foram bem inferiores aos da maltose e menores do que os hidrolisados da mandioca e não 
foram detectados apenas na concentração de 10\%, nos períodos de 10 e 30 minutos de exposição a $\alpha$-amilase bacteriana. O maior valor foi obtido no binômio concentração/tempo $30 / 10 \mathrm{com} 6 \%$ de glicose cerca de 7,6 vezes inferior ao teor de maltose.

Slominska \& Starogardzka (1986) trabalhando com amido de batata com $30 \%$ de sólidos obtiveram, após 48 horas de sacarificação, um hidrolisado com DE 52 contendo $75,5 \%$ de maltose e 6,3\% de glicose.

Venturini Filho \& Cereda (1998) produziram um hidrolisado contendo $54,23 \%$ de maltose e $4,98 \%$ de glicose a partir de tratamento de fécula de mandioca com $\alpha$-amilase bacteriana a $95^{\circ} \mathrm{C}$ por 45 minutos e $\alpha$-amilase fúngica por 6 horas a $60^{\circ} \mathrm{C}$.

De modo geral os teores de maltose apresentados nesta pesquisa foram um pouco mais baixos do que os encontrados na literatura. Estes teores mais baixos podem ser explicados pelo fato de que foram produzidos a partir da mandioca e da puba sem a extração do amido. Quando Kearsley \& Tabiri (1979) compararam a ação da $\alpha$-amilase em milho e em amido de milho nas mesmas condições obtiveram DE 15 e 25 respectivamente significando que o amido de milho é mais suscetível a hidrólise do que o uso direto do milho.

Os resultados obtidos neste trabalho são semelhantes aos encontrados para os xaropes comerciais. $O$ xarope de alta maltose de milho comercial que foi analisado por Venturini Filho\& Cereda (1998) continha 43,69\% de maltose e $10,76 \%$ de glicose é muito semelhante ao obtido no tratamento 30/10 da mandioca. Gaouar et al. (1997b) analisaram um xarope comercial de maltose com DE $45-48$ contendo $50 \%$ de maltose e $5 \%$ de glicose que também tem a composição próxima àobtida nos experimentos aqui apresentados. 


\subsubsection{Eficiência de hidrólise}

O percentual de consumo de matéria seca em relação ao teor de sólidos iniciais exprime a eficiência de hidrólise cujos resultados podem ser observados na Tabela 9.

Tabela 9. Rendimento da hidrolise do amido contido nas amostras de mandioca e puba

\begin{tabular}{c|cc}
\hline \multirow{2}{*}{$\begin{array}{c}\text { Tratamentos } \\
\text { (conc./tempo) }\end{array}$} & \multicolumn{2}{|c}{ Eficiência de hidrólise (\%) } \\
\cline { 2 - 3 } & Mandioca & Puba \\
\hline $10 / 10$ & $58,2 \mathrm{a}$ & $41,1 \mathrm{abc}$ \\
$10 / 20$ & $59,1 \mathrm{a}$ & $33,3 \mathrm{c}$ \\
$10 / 30$ & $57,0 \mathrm{a}$ & $34,5 \mathrm{c}$ \\
$20 / 10$ & $39,4 \mathrm{~b}$ & $52,1 \mathrm{a}$ \\
$20 / 20$ & $37,3 \mathrm{~b}$ & $50,1 \mathrm{ab}$ \\
$20 / 30$ & $36,4 \mathrm{~b}$ & $48,3 \mathrm{ab}$ \\
$30 / 10$ & $32,4 \mathrm{~b}$ & $40,9 \mathrm{abc}$ \\
$30 / 20$ & $30,8 \mathrm{~b}$ & $37,3 \mathrm{bc}$ \\
$30 / 30$ & $33,1 \mathrm{~b}$ & $38,4 \mathrm{bc}$ \\
\hline
\end{tabular}

*Valores acompanhados com a mesma letra não são diferentes ao nível de $5 \%$ de significância.

Eficiências mais elevadas durante a hidrólise da mandioca foram obtidas nos tratamentos com $10 \%$ de sólidos, porém isso pode ser devido a maior dificuldade de separação dos sólidos ocasionando perda de material antes da secagem. Para a puba os resultados mais altos foram alcançados com $20 \%$ de sólidos. O tratamento 20/10 apresentou eficiência maior do que os demais. 
A eficiência da hidrólise foi maior nas amostras da puba do que nas amostras de mandioca exceto na concentração de 10\% de sólidos. Provavelmente isso pode ter ocorrido devido à não formação de grumos nas amostras de puba (Mendes, 1992).

Valetudie et al. (1993) relataram que após 24 horas $44 \%$ de amido foi hidrolisado com $\alpha$-amilase de Bacillus subtilis e $52 \%$ de amido foi hidrolisado com $\alpha$-amilase pancreática enquanto Gaouar et al. (1997b) relataram conversão de $60 \%$ quando foi usada apenas a Maltogenase, uma exo- $\alpha$ amilase de Bacillus subtilis, em amido liquefeito.

Os resultados mais baixos obtidos neste trabalho podem ser atribuídos a utilização da mandioca e da puba sem a extração prévia do amido ou ao emprego do outro tipo de enzima.

\subsubsection{Balanço de massa}

O balanço de massa fornece informações sobre o rendimento final, acumulo de produtos intermediários e formação de sub-produtos e resíduos de um processo industrial.

A Figura 9 exemplifica em fluxograma a seqüência dos cálculos do balanço de massa para o tratamento da puba com $20 \%$ de sólidos e durante 10 minutos de liquefação nas diferentes etapas do processo. As Tabelas 10 e 11 trazem, em resumo, os resultados dos balanços para todos os tratamentos de mandioca e de puba respectivamente. 


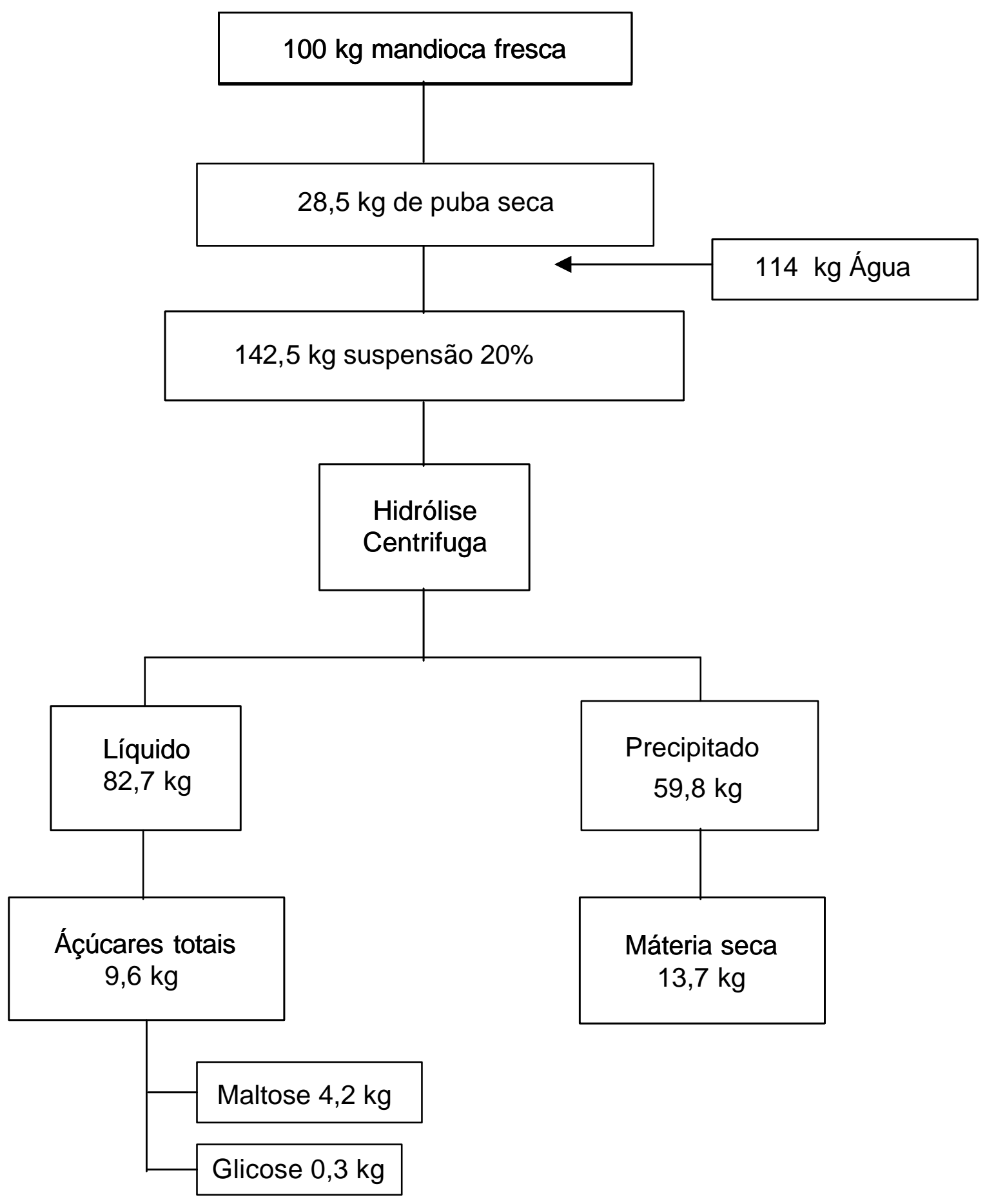

Figura 9 - Fluxograma do balanço de massa do tratamento 20/10 da puba. 
Tabela 10. Balanço de massa dos tratamentos da mandioca.

\begin{tabular}{lccccccccc}
\hline \hline Tratamentos & $10 / 10$ & $10 / 20$ & $10 / 30$ & $20 / 10$ & $20 / 20$ & $20 / 30$ & $30 / 10$ & $30 / 20$ & $30 / 30$ \\
\hline \hline Mandioca fresca (kg) & 100 & 100 & 100 & 100 & 100 & 100 & 100 & 100 & 100 \\
Mandioca seca (kg) & 28,2 & 28,2 & 28,2 & 28,2 & 28,2 & 28,2 & 28,2 & 28,2 & 28,2 \\
Adição de água (kg) & 253,8 & 253,8 & 253,8 & 112,8 & 112,8 & 112,8 & 65,8 & 65,8 & 65,8 \\
Total suspensão(kg) & 282 & 282 & 282 & 141 & 141 & 141 & 94 & 94 & 94 \\
Precipitado centrífuga (kg) & 95.9 & 84,6 & 104,3 & 76,1 & 87,4 & 89,1 & 58,3 & 62 & 60,2 \\
Matéria seca (kg) & 11,0 & 9,6 & 12,0 & 19,1 & 17,5 & 17,9 & 18,7 & 19,2 & 18,7 \\
Líquido sobrenadante (kg) & 186.1 & 197,4 & 177,7 & 64,9 & 53,6 & 51,9 & 35,7 & 32 & 33,8 \\
Açúcares totais (kg) & 10.2 & 10,7 & 9,6 & 8,8 & 6,2 & 5,8 & 6,2 & 5,3 & 5,4 \\
Maltose (kg) & 5.1 & 4,2 & 4,2 & 4,0 & 3,0 & 3,6 & 2,7 & 2,6 & 2,8 \\
Glicose (kg) & - & - & - & 0,7 & 0,4 & 0,2 & 0,7 & 0,5 & 0,6 \\
\hline \hline
\end{tabular}


Tabela 11 - Balanço de massa dos tratamentos da puba.

\begin{tabular}{|c|c|c|c|c|c|c|c|c|c|}
\hline Tratamentos & $10 / 10$ & $10 / 20$ & $10 / 30$ & $20 / 10$ & $20 / 20$ & $20 / 30$ & $30 / 10$ & $30 / 20$ & $30 / 30$ \\
\hline Mandioca fresca (kg) & 100 & 100 & 100 & 100 & 100 & 100 & 100 & 100 & 100 \\
\hline Puba seca (kg) & 28,5 & 28,5 & 28,5 & 28,5 & 28,5 & 28,5 & 28,5 & 28,5 & 28,5 \\
\hline Adição de água (kg) & 256,5 & 256,5 & 256,5 & 114 & 114 & 114 & 66,5 & 66,5 & 66,5 \\
\hline Total suspensão(kg) & 285 & 285 & 285 & 142,5 & 142,5 & 142,5 & 95 & 95 & 95 \\
\hline Precipitado centrífuga (kg) & 105,5 & 106 & 122 & 59,8 & 61 & 61,8 & 66,2 & 62,1 & 65,2 \\
\hline Matéria seca (kg) & 17,6 & 17,7 & 20,6 & 13,7 & 14,5 & 14,5 & 16,7 & 18,1 & 18,8 \\
\hline Líquido sobrenadante (kg) & 179,5 & 179 & 163 & 82,7 & 81,5 & 80,7 & 28,8 & 32,9 & 29,8 \\
\hline Açúcares totais (kg) & 6,6 & 6,3 & 4,87 & 9,6 & 8,4 & 9,5 & 5,0 & 5,8 & 5,5 \\
\hline Maltose (kg) & 2,0 & 2,3 & 1,4 & 4,2 & 4,0 & 3,6 & 2,3 & 3,1 & 2,4 \\
\hline Glicose (kg) & - & 0,3 & - & 0,3 & 0,2 & 0,2 & 0,3 & 0,3 & 0,3 \\
\hline
\end{tabular}


Utilizando $100 \mathrm{~kg}$ de mandioca obter-se-ia $28,5 \mathrm{~kg}$ de puba seca que adicionados a $114 \mathrm{~kg}$ de água formariam $142,5 \mathrm{~kg}$ de suspensão com $20 \%$ de sólidos. Aplicando-se o tratamento 20/10, ou seja, utilizando-se a $\alpha$-amilase bacteriana por 10 minutos e seguida da sacarificação e centrifugação, obteriamse 9,6 kg de açúcares totais, dos quais 4,2 kg seriam maltose e 0,3 kg seria glicose. Formariam ainda, 13,7 kg de resíduos sólidos.

Os teores mais elevados de açúcares totais foram obtidos com a mandioca nos tratamentos de concentração de $10 \%$ de sólidos que proporcionaram também os maiores índices de maltose. Para a puba os tratamentos com $20 \%$ de sólidos foram os que apresentaram os maiores índices de açúcares totais e também as maiores quantidades de maltose.

Verifica-se também que os tratamentos da puba atingiram menores níveis de glicose do que os tratamentos com mandioca.

É interessante observar que, apesar dos tratamentos de mandioca com $30 \%$ de sólidos terem apresentado menores quantidades de maltose (Tabela 10), os teores de maltose no hidrolisado, nesses tratamentos, foram maiores (Tabela 8). Isso pode ter ocorrido porque o conteúdo de açúcares totais no líquido sobrenadante também foi mais baixo. Uma separação mais eficiente ou lavagens no precipitado poderiam otimizar esse rendimento. $O$ mesmo ocorreu com os tratamentos 10/20 e 30/10 da puba atingindo ambos $2,3 \mathrm{~kg}$ de maltose ao final do processo embora a porcentagem de maltose nos açúcares totais tenha sido maior no tratamento 30/10 (Tabela 8).

Comparando os números apresentados nos balanços de massa pode-se observar que a quantidade de água utilizada para cada concentração, tanto para a mandioca quanto para puba, é totalmente diferente variando entre 256,5 $\mathrm{kg}$ e $65,8 \mathrm{~kg}$. O consumo de água pode ser um fator decisivo para indicar qual a concentração de sólidos a ser utilizada no processo. Além do consumo maior de água, os tratamentos com concentrações menores requereriam equipamentos com capacidades muito maiores do que os tratamentos com 
concentrações de sólidos maiores e exigiria mais quantidade de energia para evaporação.

Comparando os tratamentos quanto a matéria seca do resíduo pode-se observar que para a mandioca (Tabela 10) os tratamentos com $10 \%$ de sólidos apresentaram os menores índices de matéria seca no resíduo. Para a puba (Tabela 11), os tratamentos com $20 \%$ de sólidos foram os que apresentaram menores quantidades de matéria seca. Os tratamentos da mandioca, de uma forma geral, apresentaram níveis mais altos de resíduo seco.

Pode-se perceber que, tanto para a mandioca quando para a puba, os tratamentos com menores quantidades de resíduo também foram os que apresentaram maiores quantidades de açúcares totais e maltose.

Os tratamentos 10/10 com mandioca, que atingiu $5,1 \mathrm{~kg}$ de maltose para cada $100 \mathrm{~kg}$ de mandioca fresca, e o tratamento 20/10 com a puba, que atingiu $4,2 \mathrm{~kg}$ para cada $100 \mathrm{~kg}$ de mandioca fresca, foram os mais eficientes apresentando também os menores teores de resíduo sólido. Porém esses tratamentos não são os que apresentaram as maiores concentrações de maltose no hidrolisado (Tabela 8). Isso indica que se for possível melhorar a etapa de extração dos sólidos solúveis, aumenta-se a eficiência de hidrólise e alcançam-se conteúdos maiores de maltose.

Sob as condições deste experimento o tratamento 20/10 com puba pode ser considerado o melhor pois apesar de não ter apresentado a maior produção de maltose (fica pouco abaixo dos tratamentos com 10\% de sólidos da mandioca) o processo economiza água e reduz a capacidade dos equipamentos necessários, além disso os hidrolisados produzidos a partir da puba apresentaram melhor consistência, maior homogeneidade, ausência de odor desagradável, sem coloração e ainda o conteúdo de glicose foi menor do que os hidrolisados produzidos com a mandioca. 


\section{CONCLUSÕES}

- Os hidrolisados obtidos com a mandioca e a puba ra concentração de $20 \%$ de sólidos apresentaram melhor consistência e maior facilidade de manuseio.

- $\quad$ Os hidrolisados obtidos da puba apresentaram maiores facilidades de manuseio do que os da mandioca porque durante sua produção apresentaram características mais homogêneas (sem formar de grumos), permitindo melhor separação dos sólidos.

- Os hidrolisados de puba apresentaram ainda características mais vantajosas para etapas posteriores de purificação e concentração por que não formaram coloração e odores desagradáveis como os hidrolisados de mandioca.

- $\quad$ O tempo de ação da $\alpha$-amilase bacteriana na etapa da liquefação não influenciou significativamente o grau de sacarificação das amostras. Portanto é possível utilizar apenas 10 minutos para liquefação.

- Amostras com maiores concentrações de sólidos resultaram em valores de DE mais elevados após 48 horas de sacarificação.

- $\quad$ O perfil de carboidratos das amostras hidrolisadas foi semelhante aos dos xaropes comerciais com alto conteúdo de maltose. 
- A diferença do consumo de água nos diversos tratamentos pode fazer diferença na escolha do processo a ser utilizado.

- As maiores quantidades de maltose foram obtidas com a concentração de $10 \%$ de sólidos para a mandioca e de $20 \%$ de sólidos para a puba.

- Tanto para a mandioca quando para a puba, os tratamentos que resultaram em menores quantidades de resíduo no final do processo também proporcionaram maiores quantidades de açúcares totais e maltose.

- Os tratamentos da puba propiciaram menores níveis de glicose do que os tratamentos com mandioca.

- Sob as condições deste experimento o tratamento 20/10 com puba pode ser considerado o melhor porque proporcionou maior conteúdo de maltose atingindo $4,2 \mathrm{~kg}$ por $100 \mathrm{~kg}$ de mandioca fresca e menor quantidade de resíduo $(13,7 \mathrm{~kg})$.

- Tanto a mandioca quanto a puba podem ser utilizadas como alternativa de matéria-prima para a obtenção de xarope de maltose. 


\section{ANEXOS}


Anexo A - Resultados de análise de açúcares mediante cromatografia líquida.

\begin{tabular}{|l|c|c|c|c|}
\hline \multirow{2}{*}{ Amostra } & \multicolumn{4}{|c|}{ Gramas por 100 $\mathrm{mL}$ da amostra analisada } \\
\cline { 2 - 5 } & Glicose & Frutose & Sacarose & Maltose \\
\hline & & & & \\
\hline MAND 10/10 & $<0,02$ & $<0,02$ & $<0,03$ & 1,37 \\
\hline MAND 10/20 & $<0,02$ & $<0,02$ & $<0,03$ & 1,07 \\
\hline MAND 10/30 & $<0,02$ & $<0,02$ & $<0,03$ & 1,17 \\
\hline & & & & \\
\hline MAND 20/10 & 0,52 & $<0,02$ & $<0,03$ & 3,07 \\
\hline MAND 20/20 & 0,38 & $<0,02$ & $<0,03$ & 2,83 \\
\hline MAND 20/30 & 0,19 & $<0,02$ & $<0,03$ & 3,42 \\
\hline & & & & \\
\hline MAND 30/10 & 0,93 & 0,05 & 0,10 & 3,78 \\
\hline MAND 30/20 & 0,85 & $<0,02$ & $<0,03$ & 4,10 \\
\hline MAND 30/30 & 0,90 & $<0,02$ & $<0,03$ & 4,17 \\
\hline & & & & \\
\hline & & & & $<, 03$ \\
\hline PUBA 10/10 & $<0,02$ & $<0,02$ & $<0,03$ & 0,56 \\
\hline PUBA 10/20 & 0,09 & 0,08 & 0,12 & 0,65 \\
\hline PUBA 10/30 & $<0,02$ & $<0,02$ & $<0,03$ & 0,43 \\
\hline & & & & 2,55 \\
\hline PUBA 20/10 & 0,16 & $<0,02$ & $<0,03$ & 2,42 \\
\hline PUBA 20/20 & 0,13 & $<0,02$ & $<0,03$ & \\
\hline PUBA 20/30 & 0,15 & $<0,02$ & $<0,03$ & 2,20 \\
\hline & & & & 3,96 \\
\hline PUBA 30/10 & 0,52 & 0,03 & $<0,03$ & 4,65 \\
\hline PUBA 30/20 & 0,44 & $<0,02$ & $<0,03$ & \\
\hline PUBA 30/30 & 0,43 & $<0,02$ & $<0,03$ & 3,93 \\
\hline & & & & \\
\hline
\end{tabular}


Anexo B - Análises estatísticas dos tratamentos da mandioca em relação ao tempo de sacarificação.

\begin{tabular}{|c|c|c|c|c|c|c|c|c|c|}
\hline \multirow{2}{*}{$\begin{array}{c}\text { Tempo de } \\
\text { sacarificação (h) }\end{array}$} & \multicolumn{9}{|c|}{ Grau de sacarificação (DE) } \\
\hline & $10 / 10$ & $10 / 20$ & $10 / 30$ & $20 / 10$ & $20 / 20$ & $20 / 30$ & $30 / 10$ & $30 / 20$ & $30 / 30$ \\
\hline 0 & $24,4 \mathrm{~b}$ & $22,1 \mathrm{~b}$ & $21,3 \mathrm{~b}$ & $29,4 b$ & $30,2 \mathrm{~b}$ & 28,8 b & $28,5 \mathrm{~d}$ & $30,4 \mathrm{~b}$ & $29,1 \mathrm{~b}$ \\
\hline 4 & $41,3 a b$ & 37,7 a & $38,1 \mathrm{ab}$ & 45,6 a & 45,2 a & 43,2 a & $41,9 \mathrm{c}$ & 43,1 a & 42,7 a \\
\hline 8 & $42,4 a b$ & 39,9 a & $38,3 \mathrm{ab}$ & $48,5 \mathrm{a}$ & 46,1 a & 44,8 a & 43,9 bc & 43,4 a & $44,0 \mathrm{a}$ \\
\hline 12 & 44,1 a & 40,7 a & $40,1 \mathrm{ab}$ & 48,4 a & 46,9 a & 46,1 a & 44,7 bc & 44,0 a & 46,7 a \\
\hline 22 & $45,4 a$ & 44,5 a & 42,1 a & $51,4 \mathrm{a}$ & 50,9 a & 52,3 a & $50,5 a b$ & $50,7 \mathrm{a}$ & 47,6 a \\
\hline 28 & $42,3 a b$ & 37,5 a & $38,9 a b$ & 51,7 a & 49,4 a & 48,5 a & $49,9 a b c$ & 50,0 a & $48,8 \mathrm{a}$ \\
\hline 36 & $42,7 \mathrm{a}$ & 39,7 a & $40,0 a b$ & $53,2 \mathrm{a}$ & 50,3 a & 48,0 a & $47,7 \mathrm{abc}$ & 50,1 a & 48,8 a \\
\hline 48 & 44,6 a & $43,9 a$ & $37,5 \mathrm{ab}$ & 52,1 a & 51,6 a & 49,1 a & 53,5 a & $50,3 a$ & 51,9 a \\
\hline
\end{tabular}

*Valores acompanhados com a mesma letra não são diferentes ao nível de 5\% de significância. 
Anexo C - Análises estatísticas dos tratamentos da puba em relação ao tempo de sacarificação.

\begin{tabular}{|c|c|c|c|c|c|c|c|c|c|}
\hline \multirow{2}{*}{$\begin{array}{c}\text { Tempo de } \\
\text { sacarificação (h) }\end{array}$} & \multicolumn{7}{|c|}{ Grau de sacarificação (DE) } \\
\cline { 2 - 9 } & $10 / 10$ & $10 / 20$ & $10 / 30$ & $20 / 10$ & $20 / 20$ & $20 / 30$ & $30 / 10$ & $30 / 20$ & $30 / 30$ \\
\hline 0 & $0,5 \mathrm{~b}$ & $0,6 \mathrm{~b}$ & $0,9 \mathrm{~b}$ & $18,7 \mathrm{~b}$ & $13,7 \mathrm{~b}$ & $8,8 \mathrm{c}$ & $29,1 \mathrm{c}$ & $27,8 \mathrm{c}$ & $30,3 \mathrm{c}$ \\
4 & $15,1 \mathrm{a}$ & $14,2 \mathrm{a}$ & $11,8 \mathrm{a}$ & $41,4 \mathrm{a}$ & $43,5 \mathrm{a}$ & $33,0 \mathrm{~b}$ & $43,8 \mathrm{~b}$ & $45,3 \mathrm{~b}$ & $43,7 \mathrm{ab}$ \\
8 & $15,8 \mathrm{a}$ & $15,1 \mathrm{a}$ & $15,4 \mathrm{a}$ & $43,3 \mathrm{a}$ & $41,4 \mathrm{a}$ & $35,3 \mathrm{ab}$ & $44,7 \mathrm{ab}$ & $47,8 \mathrm{~b}$ & $44,3 \mathrm{ab}$ \\
12 & $17,0 \mathrm{a}$ & $16,5 \mathrm{a}$ & $14,6 \mathrm{a}$ & $44,8 \mathrm{a}$ & $42,3 \mathrm{a}$ & $37,5 \mathrm{ab}$ & $46,3 \mathrm{ab}$ & $46,5 \mathrm{~b}$ & $41,9 \mathrm{~b}$ \\
22 & $19,7 \mathrm{a}$ & $18,6 \mathrm{a}$ & $16,9 \mathrm{a}$ & $46,9 \mathrm{a}$ & $46,4 \mathrm{a}$ & $42,9 \mathrm{ab}$ & $51,3 \mathrm{ab}$ & $50,2 \mathrm{ab}$ & $46,1 \mathrm{ab}$ \\
28 & $21,2 \mathrm{a}$ & $21,6 \mathrm{a}$ & $17,4 \mathrm{a}$ & $45,5 \mathrm{a}$ & $47,2 \mathrm{a}$ & $42,8 \mathrm{ab}$ & $51,7 \mathrm{ab}$ & $49,8 \mathrm{ab}$ & $47,5 \mathrm{ab}$ \\
48 & $20,0 \mathrm{a}$ & $19,0 \mathrm{a}$ & $17,5 \mathrm{a}$ & $47,5 \mathrm{a}$ & $45,1 \mathrm{a}$ & $40,8 \mathrm{ab}$ & $50,9 \mathrm{ab}$ & $45,8 \mathrm{~b}$ & $47,2 \mathrm{ab}$ \\
& $22,4 \mathrm{a}$ & $20,7 \mathrm{a}$ & $19,0 \mathrm{a}$ & $50,3 \mathrm{a}$ & $48,6 \mathrm{a}$ & $43,5 \mathrm{a}$ & $55,1 \mathrm{a}$ & $56,8 \mathrm{a}$ & $53,3 \mathrm{a}$ \\
\hline
\end{tabular}

*Valores acompanhados com a mesma letra não são diferentes ao nível de $5 \%$ de significância. 


\section{REFERÊNCIAS BIBLIOGRÁFICAS}

ALMEIDA, P.F. Processamento e caracterização da puba. Campinas, 1992. 116p. Tese (Doutorado) - Universidade de Campinas.

ASCHENGREEN, N.H.; NIELSEN, B.H. Liquefaction, saccharification and isomerization of starches from sources other than maize. Starch/Stärke, v.31, n.2, p.64-66,1979.

ASSOCIATION OF OFFICIAL ANALYTICAL CHEMISTS. Official Methods of Analysis. 13.ed. Washington: AOAC, 1980.

BACILA, M. Curso de fisiologia de microrganismo. Curitiba: Universidade Federal do Paraná, Instituto de Bioquímica, 1960. 209p.

BERGHOFER, E.; SARHADDAR, S. Production of glucose and high fructose syrup by enzymatic direct hydrolysis of cassava roots. Process Biochemistry, p.188-194, Dec. 1988.

BOBBIO, F.O.; BOBBIO, P.A. Introdução à química de alimentos. São Paulo: Varela, 1992. 223p.

CAMARGO, C.E.D. Mandioca: o "pão caboclo", de alimento a combustível. São Paulo: Ícone, 1985. 66p.

DZIEDZIC, S.Z.; KEARSLEY, M.W. Glucose syrups: science and technology. New York: Elselvier Applied Science Publishers, 1984. 276p. 
EMPRESA BRASILEIRA DE PESQUISA AGROPECUÁRIA. Mandioca e fruticultura. http.//www.cnpmf.embrapa.br (12 set. 2002).

GAOUAR, O.; AYMARD, C.; ZAKHIAN, N. et al. Enzymatic hydrolysis of cassava starch into maltose in a continuous membrane reactor. Journal of Chemical Technology and Biotechnology, v.69, n.3, p.367-375,1997a.

GAOUAR, O.; AYMARD, C.; ZAKHIAN, N. et al. Kinetic studies on the hydrolysis of soluble and cassava starches by maltogenase. Starch/Stärke, v.49, n.6, p.231-237, 1997b.

GHILDYAL, N.P.; RAMAKRISHNA, M.; LONSANE B.K. Comparative economics of the production of high fructose syrup from cassava chips and cassava starch. Starch/Stärke, v.41, n.2, p.64-68, 1989.

GOERING, K.J.; DeHAAS, B W.; CHAPMAN, D.W. et al. New process for production of ultra high maltose syrup from special genetically derived barley. Starch/Stärke, v.32, n.10, p.349-352, 1980.

GORINSTEIN, S.; LII, C. The effects of enzyme hydrolysis on the properties of potato, cassava and amaranth starches. Starch/Stärke, v.44, n.12, p.461466, 1992.

HOOVER, R. Composition, molecular structure, and physicochemical properties of tuber and root starches: a review. Carbohydrate Polymers, v.45, n.3, p.253-267, 2001.

INSTITUTO BRASILEIRO DE GEOGRAFIA E ESTATíSTICA. Anuário estatístico do Brasil. Rio de Janeiro, 1996. v.56.

INSTITUTO BRASILEIRO DE GEOGRAFIA E ESTATístICA. Produção agrícola municipal. http.//www.ibge.org.br (15 jul. 2002). 
JOHNSON, J.C. Specialized sugars for the food industry. New Jersey: Noyes Data Corporation, 1976. 359p. (Food Technology Review, 35).

KEARSLEY, M.W.; TABIRI, J.N. The enzymic hydrolysis of starch containing crops. Lebensmittel-Wissenschaft \& Technologie, v.12, n.4, p.199-202, 1979.

LAGES, A.C.A.; TANNENBAUM, S.R. Production of glucose from tapioca (cassava starch) and farinha de mandioca (cassava meal). Journal of Food Science, v.43, n.3, p.1012-1014, 1978.

MALDONADO, H.G.; LOPEZ, O.P. Amylolytic enzymes and products derived from starch: a review. Critical Reviews in Food Science and Nutrition, v.35, n.5, p.373-403, 1995.

MENDES, B.A. Obtenção, caracterização e utilização de puba como matériaprima na produção de etanol. Campinas, 1992. 176p. Tese (Doutorado) Faculdade de Engenharia de Alimentos, Universidade Estadual de Campinas.

MENEZES, T.J.B. Etanol, o combustível do Brasil. São Paulo: Agronômica Ceres, 1980. 233p.

MILLER, G.L. Use of dinitrosalicilic acid reagent for determination of reducing sugar. Analytical Chemistry, v.31, p.426-431, 1959.

NIGAM, P.; SINGH, D. Enzyme and microbial systems involved in starch processing. Enzyme and Microbial Technology, v.17, n.9, p.770-778, 1995. 
PARK, Y.K.; BÄR, W.H.; PAPINI, R.S. Relação entre intumescimento, gelatinização e suscetibilidade dos amilos de mandioca e de milho à alfa amilase bacteriana. Revista Brasileira de Tecnologia, v.2, n.2, p.95-99, 1971.

PLUMBLEY, R.A; RICKARD, J.E. Post-harvest deterioration of cassava. Tropical Science, v.31, p.295-303, 1991.

PONTOH, J.; LOW, N.H. Glucose syrup production from Indonesian palm and cassava starch. Food Research International, v.28, n.4, p.379-385, 1995.

SAHA, B.C.; ZEIKUS, J.G. Biotechnology of maltose syrup production. Process Biochemistry, v.22, n.3, p.78-82, 1987.

SARIKAYA, E.; HIGASA, T.; ADACHI, M.; MKAMI, B. Comparison of abilities of $\alpha$ - and $\beta$-amylases on raw starch granules. Process Biochemistry, v.35, n.7, p.711-715, 2000.

SATO, H.H.; PARK, Y.K. Production of maltose from starch by simultaneous action of beta amylase and flavobacterium isoamylase. Starch/Stärke, v.32, n.10, p.352-355, 1980.

SHAW, J.F.; SHEU, J.R. Production of high-protein flour from rice by an enzymatic method. Bioscience Biotechnology and Biochemistry, v.56, n.7, p.1071-1073, 1992.

SIMS, K.A.; CHERYAN, M. Continuous production of glucose syrup in an ultrafiltration reactor. Journal of Food Science, v.57, n.1, p.163-166, 1992.

SLOMINSKA, L.; STAROGARDZKA, G. Studies on the application of maltogenic amylase in the production of maltose containing syrup. Starch/Stärke, v.38, n.6, p.205-210, 1986. 
VALETUDIE, J.C.; COLONNA, P.; BOUCHET, B.; GALLANT, D.J. Hydrolysis of tropical tuber starches by bacterial and pancreatic $\alpha$-amylases. Starch/Stärke, v.45, n.8, p.270-276, 1993.

VENTURINI FILHO, W.G.; CEREDA, M.P. Hidrolisado de fécula de mandioca como adjunto de malte na fabricação de cerveja: avaliação química e sensorial. Ciência e Tecnologia de Alimentos, v.18, n.2, p.156-161, 1998.

VILLELA, G.G.; BACILA, M.; TASTALDI, H. Técnicas e experimentos de Bioquímica. Rio de Janeiro: Guanabara Koogan, 1973. 552p. 